\title{
Tanaididae (Crustacea, Tanaidacea, Tanaidomorpha, Tanaidoidea) on a Floating Dock, West Beach, Adelaide, South Australia: Introduced or Indigenous?
}

\author{
VALERIE K. TAIT ${ }^{1 *}$, KATHLEEN E. CONLAN ${ }^{1,3} \&$ SABINE DITTMANN ${ }^{2}$ \\ ${ }^{1}$ Canadian Museum of Nature, P.O. Box 3443, Station D, Ottawa, Ontario, K1P 6P4, Canada \\ ${ }^{2}$ Flinders University, College of Science \& Engineering, GPO Box 2100, Adelaide, SA 5001, Australia \\ I"sabine.dittmann@flinders.edu.au; @ ittps://orcid.org/0000-0002-9408-2734 \\ ${ }^{3}$ !" kconlan@nature.ca; 1 https://orcid.org/0000-0002-2263-7075 \\ "Corresponding author. ="val.k.tait@gmail.com; @ https://orcid.org/0000-0002-7666-7421
}

\begin{abstract}
Floating artificial structures provide sites for fouling communities and favourable habitat for the establishment of nonindigenous species. Two species of Tanaididae dominated crustacean biota in a one year time-series sampling of macroalgae on the floating dock at the West Beach boat ramp, Adelaide, South Australia. This paper provides identifications for these two species and discusses inter- and intra-species variability considering the available body of morphological and molecular information. We have given one species a new species designation, Tanais adelaidensis n. sp. The other has a 655 nucleotide CO1 sequence matching that of Hexapleomera sasuke Tanabe \& Kakui, 2019 collected in Japan, also matching a shorter $\mathrm{CO} 1$ sequence for a described Zeuxo Templeton, 1840 species from the Eastern Mediterranean. This work underlines the utility and need for detailed morphological and molecular data to resolve the taxonomy and biogeography of fouling and holdfast community tanaids, particularly those that have the demonstrated potential for a history of transport between geographically distant sites.
\end{abstract}

Key words: Hexapleomera, Tanais, Zeuxo, marine fouling, CO1

\section{Introduction}

Marine invasive and non-indigenous species are of growing concern for biodiversity (Bax et al. 2003; OcchipintiAmbrogi \& Galil 2010) but their detection can be challenging (Darling \& Carlton 2018). In regions without complete inventories of biodiversity or insufficient knowledge of geographic distributions of marine species, biological introductions can remain unrecognised. This is particularly the case when taxonomy is unresolved (Marchini \& Cardeccia 2017). Main vectors for transport of marine species include ballast water, hull fouling, aquaculture, and increasingly marine debris (Hewitt et al. 2004; Rech et al. 2018). For small crustaceans such as amphipods, isopods and tanaids which lack a pelagic larval stage, hull fouling is a possible means for human-mediated long-distance dispersal (Larsen 2005; Marchini \& Cardeccia 2017). Further regional spread of non-indigenous species can occur via hull fouling on recreational vessels (Wasson et al. 2001; Ashton et al. 2006; Burgin \& Hardiman 2011; Martínez-Laiz et al. 2018) and marinas have been recognised as hubs for transfer (Ulman et al. 2017). Non-indigenous and cryptogenic species (of undetermined origin) are more prominent on hard substrates, especially among fouling communities on artificial structures and pilings (Hewitt et al. 2004; Glasby et al. 2007; Albano \& Obenat 2019). Floating artificial structures, in particular, are colonised by non-indigenous species (Leclerc et al. 2020). While crustaceans are among the more common marine invaders (Hewitt et al. 2004; Ruiz et al. 2015), tanaids are rarely included in records of introduced species. Ahyong \& Wilkens (2011) list only one species of Tanaidacea (Tanais dulongii (Audouin, 1826)) as non-indigenous to Australia.

Lifestyle factors such as brood care, absence of a pelagic larval stage, and limited swimming ability suggest that Tanaidacea are unlikely to have widespread distributions when acted on solely by natural processes (Larsen $e t$ al. 2015). Detailed morphological studies and molecular data have provided evidence refuting earlier suggestions of cosmopolitan distributions of several Tanaidacea (Sieg 1980; Bamber 2012a; Błażewicz-Paszkowycz et al. 2012; 
Larsen et al. 2014; Larsen 2014). However, Tanaidacea of the genus Hexapleomera Dudich, 1931 (Family Tanaididae Nobili, 1906) were found on the hulls of yachts (Bamber 2012a) and in fouling communities from harbours (Tanabe \& Kakui 2019) and fish farms (Esquete \& Fernandez-Gonzalez 2016). They are also epibionts on loggerhead sea turtles (Moore 1894; Sieg 1980; Edgar 2008; Tanabe et al. 2017; Tanabe \& Kakui 2019) and the Caribbean manatee (Morales-Vela et al. 2008). Thus, this genus has a demonstrated potential for long distance transport by both natural and human-mediated means.

The Family Tanaididae within the Tanaidacea has seen several taxonomic revisions and many new species descriptions in recent years. For example, of the 15 species of Tanaididae which Edgar (2008) recorded from shallow $(<20 \mathrm{~m})$ macroalgae, seagrass, and rocky reef habitats at locations in all Australian states, twelve were considered new to science, one of which was subsequently moved to the Hexapleomera genus as H. moverleyi (Edgar, 2008) (Bamber 2012a). Two species were given a $c f$. designation, namely Tanais $c f$. dulongii and Hexapleomera cf. robusta, the latter of which has since been given a new species designation, H. edgari Bamber, 2012. One species of Zeuxo Templeton, 1840 was considered already known but has been re-assessed (Larsen 2014) and given full species rank as Z. edgari Larsen, 2014. Diversity of Tanaidacea in Australian coastal waters is high with a considerable degree of regional distinctness (Bamber \& Błażewicz-Paszkowycz 2013). Bamber (2008) reported 29 species in 20 genera among Tanaidacea from littoral and sublittoral sediments of Moreton Bay, Queensland, whereof 20 species were new to science, including one species of Zeuxo, Z. amiti Bamber, 2008. Diversity of tanaids was also high in a survey in Western Australia, with 26 species of which 24 were new to science (Bamber 2005). Of these, five were members of the Tanaididae: two Zeuxo species (Z. angua Bamber, 2005 and Z. nannioggae Bamber, 2005); one Zeuxoides Sieg, 1980 (Z. casanunda Bamber, 2005); one Aviatanais Bamber, 2005 (A. tempestacera Bamber, 2005); and one Tanais Latreille, 1831 species (T. pongo Bamber, 2005).

Identifications in the Tanaididae are challenging due to the morphological similarity between species (e.g. Larsen \& Froufe 2010; Larsen et al. 2015), incomplete information on morphological variability within species throughout their lifecycle (Larsen 2014; Kakui et al. 2017), and the limited pool of molecular information currently available. Determining whether species are native, cryptogenic, or non-indigenous requires combinations of approaches, including both traditional morphological descriptions and, increasingly, molecular tools (Geller et al. 2010; Marchini \& Cardeccia 2017). We present here the morphological and molecular information supporting our identifications of the two dominant species of Tanaidacea found in a one year time-series of fouling community crustaceans on floating docks of a recreational boat ramp in South Australia. The objectives of the present work were to identify these two species and to assess whether they were native to Australia or introduced.

\section{Methods}

\section{Sample collection and storage}

Time-series sampling specimens. Samples were taken at 10 approximately monthly time points on the floating docks at the West Beach Boat Ramp $\left(34.958^{\circ} \mathrm{S}, 138.504^{\circ} \mathrm{E}\right)$, Adelaide, South Australia (Figure 1), from October 2009 until September 2010. This sampling site has three pontoons overlaid by segmented concrete slabs. The northfacing (sunlit) sides of three segments were sampled on each pontoon for each time point. Four groups of algae were sampled per slab: "Ulva" consisting of Ulva lactuca Linnaeus, Ulva prolifera O.F. Müller, Ulva ralfsii Harvey; "red bush" predominantly Gigartina brachiata Harvey; "green filamentous" predominantly Chaetomorpha linum (O.F. Müller) Kützing; and "red filamentous" consisting of Polysiphonia decipiens Montagne and P. (Lophosiphonia) teges Womersley. Macroalgal identifications were provided by Dr. R. N. Baldock, State Herbarium, Adelaide. Organisms associated with the algae were separated under the microscope using forceps when still living, except for some of the earlier samples. The specimens were then preserved in $70 \%$ ethanol. Formalin was not used in the preservation of the samples.

Specimens for molecular analysis. Attempts to extract quality DNA from the time-series samples stored in $70 \%$ ethanol were unsuccessful. To obtain new specimens for the molecular analysis, samples of macroalgae plus associated fauna were collected just below the waterline on the pontoons on 19 January 2015 (collected by: R. Baring and T. Ramsdale). Samples were put immediately into plastic containers containing $95 \%$ ethanol and transported back to the lab in a cooler. They were stored in the freezer $\left(-20^{\circ} \mathrm{C}\right)$ until the crustaceans were separated from the macroalgae, mostly within the 12 to 24 hours following collection. The crustaceans from each sample were then put 
in fresh $95 \%$ ethanol in plastic vials. Specimens were shipped with cold packs to the Canadian Museum of Nature. On arrival, the vials were unpacked and stored in the freezer $\left(-20^{\circ} \mathrm{C}\right)$ until DNA work 8 to 10 weeks later.

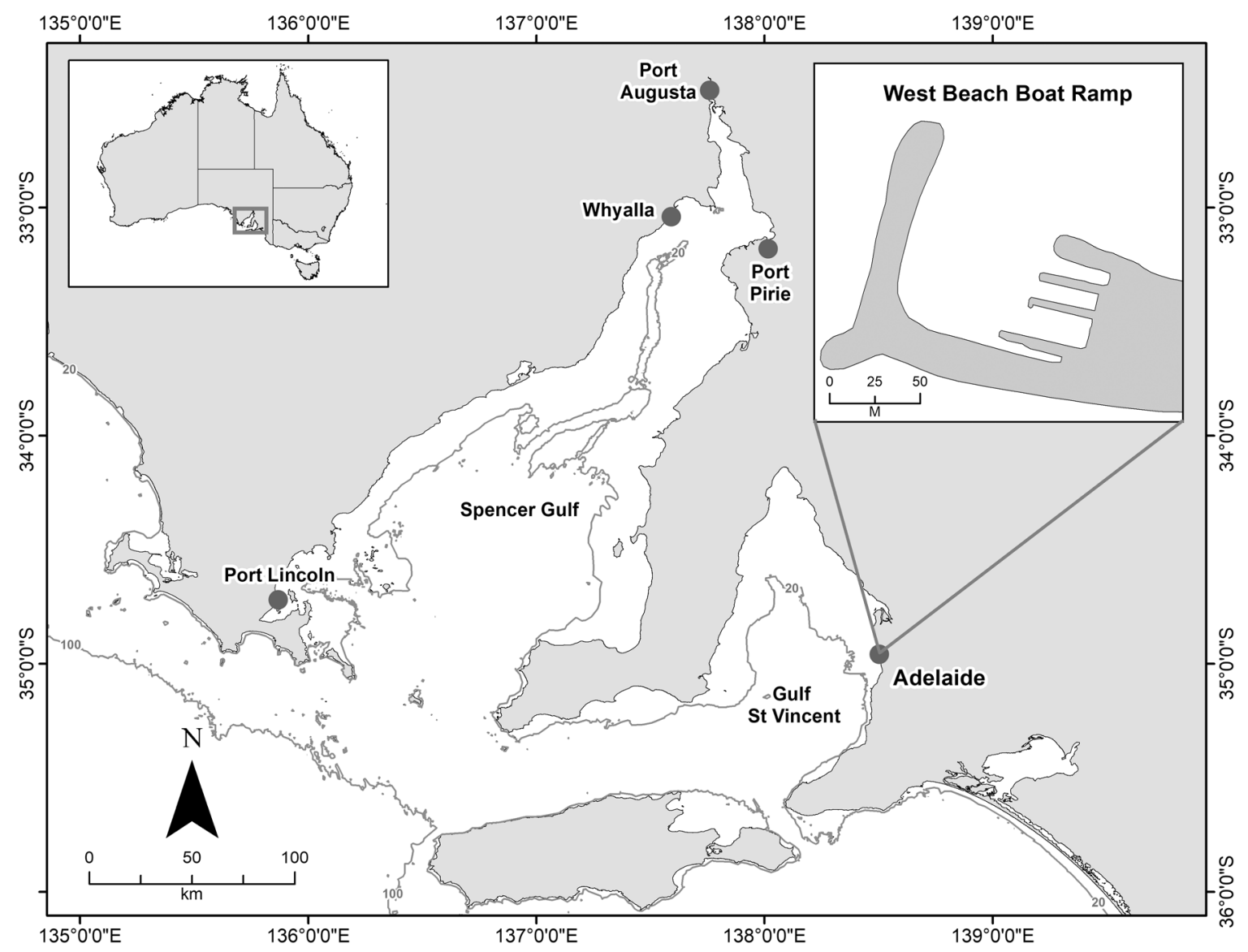

FIGURE 1. Location of West Beach Boat Ramp, Adelaide, South Australia.

\section{Morphological methods}

Dissections were done in 70\% ethanol under a Wild (Heerbrugg, Switzerland) M5 dissecting microscope, the parts transferred to glycerin, and then mounted in glycerin for viewing and measurement under the compound microscope (Wild M20).

To gain some measure of the intra-species variability, 12 specimens (five males, seven females) of the Hexapleomera species were dissected from a March 2010 sample and five specimens (three males, two females) from the January 2015 sampling. Eight specimens of the Tanais species were dissected (four males, four females) from a February 2010 sample and four (two males, two females) from the January 2015 sampling. The morphology of the January 2015 specimens was compared to that of the time-series specimens.

Body length was measured from the base of the antennules to the central apex of the pleotelson, using the dorsal view for non-flexed specimens but the lateral view when the curvature of the specimen prevented doing this. Morphological terminology largely follows Larsen (2003). In addition, serially repetitive body parts such as pereonites, parts of uropods, and antennal flagella are considered segments, but pereopod and main antennule and antennal parts articles (Bamber 2008). Medial is used for closer to the medial plane of the body, largely consistent with inner, and lateral for farther from the mid-line, i.e. outer. The abbreviation PSS is used for plumose sensory seta consistent with Tanabe et al. (2017) and crotchet, as introduced by Bird (2019), for the short, robust spiniform setae (Larsen 2003), or "spine"-like features, distal on the meri and carpi of pereopods. Voucher specimens and the complete time series will be returned to the crustacean collection of the South Australian Museum (SAMA) with a representative set for each species remaining at the Canadian Museum of Nature (CMN). 


\section{Molecular methods}

DNA extraction. Two methods were used: A silica membrane spin column method adapted from Ivanova et al. (2006) and a Chelex-100 extraction method based on Walsh et al. (1991) with modifications devised with reference to Larsen (2001), Nishiguchi et al. (2002), and Wang \& Wang (2012). Additional detail on protocols, reagents and recipes is provided in the Supplementary Material. Both methods involved grinding of specimens prior to extraction and were therefore destructive.

PCR amplification \& sequencing. Primers LCO1490 and HCO2198 (Folmer et al. 1994) were used for CO1. The PCR conditions (25- $\mu$ l reaction volumes) were those used by Larsen et al. (2014): $16.4 \mu$ l DNA-grade $\mathrm{H}_{2} \mathrm{O}, 2.5$ $\mu \mathrm{l}$ 10X PCR BIO Buffer, $1.5 \mu 150 \mathrm{mM} \mathrm{MgCl}_{2}$ [final concentration $1.5 \mathrm{mM}$ ], $0.5 \mu 110 \mathrm{mM}$ dNTP's [final concentration $200 \mu \mathrm{M}$ ], $0.5 \mu \mathrm{l} 10 \mathrm{mM}$ of each primer [final concentration $0.2 \mu \mathrm{M}$ ], $0.1 \mu \mathrm{l}$ BIOTaq DNA Polymerase, and $3 \mu \mathrm{l}$ DNA template. Two additional isolates were amplified in February 2018 using DreamTaq and the same final concentrations of reagents. As per Larsen et al. (2014), the cycle parameters applied were: initial denaturation at $94^{\circ} \mathrm{C}$ for $3 \mathrm{~min}$; denaturation at $94^{\circ} \mathrm{C}(30 \mathrm{~s})$; annealing at $52^{\circ} \mathrm{C}(45 \mathrm{~s})$; extension at $72^{\circ} \mathrm{C}(45 \mathrm{~s})$ repeated for 38 cycles; and a final extension time of $5 \mathrm{~min}$ at $72^{\circ} \mathrm{C}$.

Amplified DNA templates were purified (ExoSap) or simply diluted (February 2018) then sequenced using ABI BigDye cycle sequencing using the LCO1490 and HCO2198 primers. $10 \mu 1$ sequencing volumes contained 7 $\mu 1$ DNA-grade $\mathrm{H} 2 \mathrm{O}, 1.5 \mu \mathrm{l}$ X ABI Buffer, $0.5 \mu \mathrm{l}$ of $10 \mu \mathrm{M}$ primer working solution, $0.4 \mu 1$ BigDye Ready Reaction Mix, and $0.6 \mu \mathrm{l}$ of the PCR product. Sequences were read on an ABI-3130x1 Sequencer.

Molecular data processing. Reads were assembled using Geneious, version 8 (BioMatters Ltd., Auckland, New Zealand). The sequences were aligned using Clustal W in MEGA 7 (Kumar et al. 2016) and compared with Hexapleomera and Zeuxo or Tanais COI data available in the NCBI Nucleotide database at that time using K2P distances (MEGA 7; Kumar et al. 2016). Sequences have been submitted to the NCBI Nucleotide database.

\section{Results}

Taxonomy_Tanais Latreille, 1831

\section{Molecular data}

Identical CO1 sequence data were obtained for the two specimens of the West Beach Tanais sp. analysed (GenBank accession numbers: MW991406, MW991407; length 679 nucleotides, nt). Table 1 shows the genetic distances (K2P, Kumar et al. 2016) between these data and Tanais dulongii sequences available in GenBank (NCBI 2021). Three $C O 1$ partial sequences are available for specimens identified as $T$. dulongii, one from a specimen collected at Dania Beach, Florida (Drumm 2010; 568 nt) and two from multiple specimens collected at Mindelo, Portugal, and Helgoland, Germany (Larsen et al. 2014; 389 nt).

The West Beach Tanais sequence differs by only 2\% over the $568 \mathrm{nt}$ sequence published by Drumm (2010). The two shorter sequences for T. dulongii specimens published by Larsen et al. (2014) show a genetic distance of 13.6\% from each other and are more than 20\% distant from the Florida and West Beach specimens.

\section{Morphology \\ Family TANAIDIDAE Nobili, 1906 \\ Subfamily TANAIDINAE Nobili, 1906 \\ Genus Tanais Latreille, 1831}

Type species. Tanais dulongii (Audouin, 1826)

Genus diagnosis: (from Edgar 2008, modifications in bold). Four pleonites present plus pleotelson. Pleonites 1 and 2 carrying a transverse dorsal row of plumose setae. Antennule with four or five articles, first article at least 2.5 times length of second article in mature females, terminal articles with four to seven aesthetascs. Antenna with seven or eight articles, article 2 longer than wide, last two or three articles small. Maxillule endite with seven ( $\boldsymbol{T}$. nuwalianensis Tzeng \& Hsueh, 2014) or eight large terminal spiniform setae, palp with several long setae. Labium outer lobe with rounded terminal process, fused or not fused. Pereopod 1 coxa without anterior bulge. Pleopod 
basal articles with zero (T. pongo Bamber, 2005) to four setae (T. tinhauae Bamber \& Bird, 1997) on medial margin and seven to more than twenty (T. pongo) plumose setae on the lateral margin, endopod medial margin with about ten to twenty plumose setae. Pleopod 3 similar or slightly smaller than pleopods 1 and 2 . Uropod with three to five (T. pongo) segments, terminal segment normal. Sexual dimorphism low, observed in chelipeds, antennules, and antennae.

TABLE 1. Pair-wise genetic distances (K2P, \%) between CO1 sequences for the West Beach Tanais specimens and NCBI Nucleotide published sequences for the genus Tanais.

\begin{tabular}{|c|c|c|c|c|c|}
\hline Species & $\begin{array}{l}\text { T. adelaidensis } \\
\text { (West Beach, S. } \\
\text { Australia) }\end{array}$ & $\begin{array}{l}\text { T. dulongii } \\
\text { (Florida) } \\
\text { (Drumm 2010) }\end{array}$ & $\begin{array}{l}\text { T. dulongii } \\
\text { (Florida) } \\
\text { (Drumm 2010) }\end{array}$ & $\begin{array}{l}\text { T. dulongii (Ger- } \\
\text { many) (Larsen } \\
\text { 2014) }\end{array}$ & $\begin{array}{l}\text { T. dulongii (Por- } \\
\text { tugal) (Larsen } \\
\text { 2014) }\end{array}$ \\
\hline GenBank Accession \# & $\begin{array}{l}\text { MW991406, } \\
\text { MW991407 }\end{array}$ & HM016204.1 & HM016204.1 & $\begin{array}{l}\text { KF928325.1 } \\
\text { (isolateT125) }\end{array}$ & $\begin{array}{l}\text { KF928324.1 } \\
\text { (isolateT60) }\end{array}$ \\
\hline Sequence length, nt & 679 & 568 & 389 & 389 & 389 \\
\hline $\begin{array}{l}\text { T. adelaidensis (West Beach, } \\
\text { S. Australia) }\end{array}$ & - & 2.0 & 2.1 & 22.4 & 25.3 \\
\hline $\begin{array}{l}\text { T. dulongii (Florida) } \\
\text { (Drumm 2010) }\end{array}$ & - & - & - & 21.4 & 23.5 \\
\hline $\begin{array}{l}\text { T. dulongii (Germany) } \\
\text { (Larsen 2014) }\end{array}$ & - & - & - & - & 13.6 \\
\hline
\end{tabular}

Tanais adelaidensis n. sp.

(Figures 2-7, Table 2)

Material examined. Holotype: Ovigerous female, from Gigartina macroalgae, collected by K. Conlan, from West Beach Boat Ramp, $34.958^{\circ} \mathrm{S}, 138.504^{\circ} \mathrm{E}, 18$ February 2010, SAMA Catalogue (Cat.) Number (No.) C14331. Allotype: Mature male, among Gigartina, collected by K. Conlan, from West Beach Boat Ramp, $34.958^{\circ} \mathrm{S}, 138.504^{\circ} \mathrm{E}$, 18 February 2010, SAMA Cat. No. C14333.

Dissected. Four females (three ovigerous, 4.5, 4.4, and $4.2 \mathrm{~mm}$; one preparatory, $5.8 \mathrm{~mm}$ ) dissected from February 2010 sampling of Gigartina. Two ovigerous females $(3.6,3.7 \mathrm{~mm}$ ) dissected and additional two females (ovigerous, $3.7 \mathrm{~mm}$; preparatory, $3.7 \mathrm{~mm}$ ) sequenced for CO1 from January 2015 sampling. Three copulatory males (4.5, $4.7,4.7 \mathrm{~mm})$ and one preparatory male $(4.3 \mathrm{~mm})$ dissected from February 2010 sampling. Two copulatory males dissected (3.3, $3.4 \mathrm{~mm}$ ) from January 2015 samples.

Additional material used for size measurements. Five samples from the February time-series sampling point, with a total of 35 ovigerous females, 30 post-ovisac females, 147 preparatory females, 25 copulatory males, 104 preparatory males, 40 juvenile females, 84 juvenile males, and 642 mancae.

Species diagnosis. FEMALE. Antennule five-articled (three main and two short distal) with three or four distal aesthetascs; antenna eight-articled (five main and three short distal). Left mandible lacinia mobilis well-developed, tooth-like, distal margin with four low peaks, with two pectinate accessory setae; right lacinia mobilis peg-like, widening distally with two pectinate accessory setae. Maxilliped palp article 1 with no distal setae. Pereopod 6 with seven to eleven leaf-like setae, four to six finely biserrate setae and one elongate bipectinate seta on mediodistal margin. Pleopod 3 slightly smaller than pleopods 1 and 2. Pleopods 1 and 2 basal articles with two or three short setae on the medial margin, pleopod 3 with one or two. Uropod three-segmented (two segments and the peduncle). Pleotelson with small anterolateral processes, suggestive of residual pleonite 5.

Specimen sizes. Based on counts and sizing of five samples from February 2010 assessed in more detail, mature ovigerous and post-ovigerous (with scars) females ranged in size from 3.4-6.0 mm. Preparatory females reached a length of $6.4 \mathrm{~mm}$. Males had a transverse band of pigmentation on the ventral surface of pereonite 6 that encompassed the developing or developed gonadal pores. Males with more exaggerated chelipeds and clear penile cones and gonadal pores were 3.7-5.5 mm. Preparatory males with less developed chelipeds but with observable sexual differentiation (visible gonadal pores, cheliped fixed finger shape), to varying degrees, were 2.6-5.2 mm. The smallest specimens that had gross morphology complete with observable beginnings of sexual differentiation (tiny ovisac buds) were $1.9 \mathrm{~mm}$. Juvenile males had a transverse band of light pigmentation ventral on pereonite 6 . 
Sex ratio. For the five February samples, considering only ovigerous and post-ovigerous females and males with well-developed chelipeds and clear penile cones and gonadal pores as adult, the mean adult female to male ratio was 3.3 (median 2.8; range 1.2-5.0). Including all sizes for which sexual differentiation was observable, the mean female to male ratio across the samples was 1.3 (median 1.1; range 1.1-1.9). No intersex specimens were observed in these five samples.

Description: FEMALE. Holotype full body, SAMA Cat. No. 14331; appendages from dissected paratype, SAMA Cat. No. 14332 (Figures 2-5\&7, Table 2).

Body (Figures 2A, 2B). Body $4.9 \mathrm{~mm}$ long, 5.4x as long as maximum pereonal width. Cephalothorax 18\% of total specimen length. Cephalothorax sub-triangular, with rounded posterolateral margins, length similar to width and $0.8 \mathrm{x}$ length of pereonites 1 to 3 combined. Small triangular eyes, dark-coloured with visual elements. Two or three setae behind each eye lobe. Cephalothorax also with two or three setae on each dorsolateral surface about onethird of the way from the anterior end. Pereonite $10.4 \mathrm{x}$ length of pereonite 4 , length $0.3 \mathrm{x}$ width. Pereonite 2 wider anteriorly, $0.7 x$ length of pereonite 4 , length $0.5 x$ width. Pereonite 3 also wider anteriorly, $0.8 x$ length of pereonite 4 , length $0.6 \mathrm{x}$ width. Pereonite 4 length $0.7 \mathrm{x}$ width. Pereonite 5 similar length to pereonite 4 with length $0.7 \mathrm{x}$ width. Pereonite $60.8 \mathrm{x}$ length of pereonite 4, with length $0.6 \mathrm{x}$ width. Pereonites 4 to 6 widen posteriorly. Pereonites 1 to 3 combined are $1.3 \mathrm{x}$ as long as their maximum width. Pereonal setation sparse. Pereonite 1 with sparse setae along the anterior margin - single short seta (in some cases two) at each dorsolateral corner, and, on each side of centre, two pairs of unequal setae. Pereonite 2 with unequal pair of setae in each anterolateral region, unequal pairs of anterodorsal setae (second seta of each pair very small, not seen in all specimens examined) each side of centre, and one or two short setae in each posterolateral corner. Pereonite 3 similar to pereonite 2. Pereonites 4 to 6 similar to pereonites 2 and 3, but with as many as three unequal setae in antero-dorsolateral and posterolateral regions.

Pleon $24 \%$ of total specimen length, consisting of four pleonites and pleotelson. Pleonite 1 length $0.4 \mathrm{x}$ width and $0.7 x$ length of pereonite 6 . Pleonite $20.7 x$ length of pleonite 1 with length $0.3 x$ width. Pleonite $30.65 x$ length of pleonite 1 with length $0.3 \mathrm{x}$ width. Pleonite $40.3 \mathrm{x}$ length of pleonite 1 with length $0.2 \mathrm{x}$ width. Pleonite $40.7 \mathrm{x}$ width of pleonite 3. Pleonite 4 similar width to pleotelson. Pleotelson $0.9 x$ length of pleonite 1 , with length $0.5 x$ width. Pleonite 1 with row of plumose setae extending onto posterior region of dorsal surface from each side, almost meeting in centre; also with sparse longitudinal row of three setae dorsolaterally each side anterior to transverse plumose row. Lateral ventral margins of pleonite 1 each with row of plumose setae. Pleonite 2 setation as for pleonite 1. Pleonite 3 with row of plumose setae along lateral ventral margin joining with short row of simple setae extending onto posterolateral surface, but not further onto dorsal surface; also with dorsolateral grouping of simple setae each side of two long and one shorter seta. Pleonite 4 with short, single lateral seta each side (possibly very small additional seta visible on one side) and three or four setae (one long plus two or three short) up onto each dorsolateral surface. Pleotelson (Figure 2B) with single anterolateral seta each side on small but clear bulge (possible residual pleonite 5), posterolateral corner with single short seta on one side (but cluster of two very short setae visible on other corner and on other specimens); each side of centre a row of three (sometimes four) setae, one long the others short, and single short PSS; posterior margin with small central process carrying two pairs of simple setae.

Variability in pereonite measurements. Some variability observed in ratios of body length to maximum width and length to width ratio of pereonites 1 to 3 . Among 8 mature females with body lengths $4.0-5.8 \mathrm{~mm}$, median (range) of body length to maximum pereonite width 5.5 (4.9-6.0); ratio of cephalothorax length to pereonites 1 to 3 combined length 0.75 (0.69-0.86); cephalothorax 17.3\% (16.2-19.3\%) of body length; ratio of pereonites 1 to 3 combined length to maximum width 1.27 (1.14-1.41); and pleon length $25.0 \%$ (23.9-25.9\%) of body length. We did not find a relationship between this variability in extension of pereonites and other morphological characters.

Antennule (Figures 2C, 2D). Antennule with five articles, 0.8x length of cephalothorax. First article longer than second article $(2.4 \mathrm{x})$, length $2.1 \mathrm{x}$ width [some damage], with dorsolateral cluster of three PSS in proximal half of article (attachment sites visible, slight crush damage; confirmed on other antennule). Distally, first article with dorsolateral cluster of four simple setae and three shorter PSS, a dorsomedial pair of unequal setae, and ventromedial pair of short PSS (total distal: six simple and five PSS; range: 4-7 simple, 4 or 5 PSS). Second article 1.3x as long as wide, $0.4 \mathrm{x}$ length of first article. Distally, second article with dorsolateral cluster of four setae (two long, one medium, one short) and at least three PSS extending down to ventrolateral region (other antennule with clear view of five PSS in this location), with single simple seta and pair of unequal setae in the ventromedial region (total distal: seven simple setae, several PSS, range: 5-7 simple, >3-7 PSS). Third article slightly shorter than second article $(0.9 \mathrm{x})$, length $2.1 \mathrm{x}$ width. Distally, third article with single dorsal simple seta and, in the ventromedial region, 
two PSS and one simple seta (range: 2 or 3 simple setae, 1 or 2 PSS). Fourth and fifth articles very short (Figure 2D; with only aesthetascs and setae distal on third article shown). Fourth article with four simple setae attached in row dorsal to medial and two aesthetascs attached ventrally. Attachment site of third aesthetasc obscured by setae. Other antennule examined; clearly shows attachment of two aesthetascs to fourth article and one to fifth article. Fifth article with one short PSS, three long setae, one shorter seta, and two very short simple seta, in addition to single aesthetasc. Fourth and fifth articles together with, ten simple setae (two very short), one short PSS, and three aesthetascs (range: 3-4 aesthetascs, 8-10 simple setae, consistently 1 PSS).

Antenna (Figures 2E, 2F). Antenna same length as antennule, with eight articles, terminal three articles very short. First article without setae. Second article length $1.3 \mathrm{x}$ width, with two (only one visible on other antenna) ventromarginal setae. Distally, second article with one ventral seta, and two dorsal setae, one lateral and the other medial. Second article with extensive microtrichia on dorsal, ventral, and medial surfaces. Third article half length of second article, length $0.8 \mathrm{x}$ width, distally with single dorsal and single ventral setae (other specimens and other antenna of this specimen all with only the dorsodistal seta). Fourth article similar length to second article, length 1.9x width; distally with one long seta and one PSS in the ventral region, a single shorter dorsal seta, and two simple lateral setae of unequal lengths (total setae distally: 4 simple setae, 1 PSS; range: $3-5$ simple, 1 or 2 PSS). Fifth article longer than wide (2.0x), 0.8x length of second article; distally with two medial PSS, two simple ventromedial setae, two short PSS and one simple seta in the ventrolateral region, and one short dorsolateral PSS. Overall, this gives three simple setae and five distal PSS (range: 2 or 3 simple, 2-5 PSS). Sixth, seventh, and eight articles very short (Figure 2F; only setae on fifth and seventh articles shown). Sixth article half as long as wide, only $0.1 \mathrm{x}$ length of second article, distally with two long lateral setae and one shorter medial seta. Seventh article $0.8 \mathrm{x}$ as long as wide, $0.1 \mathrm{x}$ length of second article with four setae. Eighth article minute, also carrying four setae. Seventh and eighth articles together carry eight distal setae, in total, two of the setae shorter [some damage to the longer setae in the illustrated specimen] (range: 8 or 9 simple, 0 or 1 PSS).

Cheliped (Figure $2 \mathrm{G}$ ). Basis slightly shorter than carpus, length 1.2x width, with two unequal setae on outerfacing surface close to join with sclerite, and with two (sometimes three) unequal ventrodistal setae. Merus subtriangular, no ventrodistal indentation, with three unequal setae (two in one female) in dorsal corner, and ventrally with four setae (five in the largest specimen) about two-thirds of way along margin. Carpus length, C(L), slightly shorter than propodus length including fixed finger, $P(L)(C(L): P(L)=0.9$, range: 0.8-0.9), carpus length 1.6x width (range: 1.4-1.6). Carpus without any ventral process, dorsally with one short seta about a third of way along margin, dorsodistally with tuft of four setae (group of $3+1$ in all female specimens), ventrally with three (rarely two) unequal setae about three-quarters of way along margin; also with row of five (sometimes four) unequal setae, shortest setae at either end of row, in ventral half of distal region of lateral surface. Propodus about twice as long as wide. Propodus medial surface with single seta close to dorsodistal junction with dactylus. Fixed finger cutting edge rounded distally, smooth with slight process midway along dorsal margin, with cluster of four setae at proximal end close to junction with dactylus. Fixed finger with five (or four) ventral setae, dorsally with seven setae (nine in largest female) in row on lateral surface attached below cutting edge, and two setae on medial surface close to terminal claw. Dactylus not arcuate, as long as fixed finger, with terminal claw; ventrally with row of small setules, a medial seta, and small, obtuse triangular ventral process about mid-margin.

Mouthparts (Figures 3A-L). Labrum (Figure 3A) rhomboidal with rounded corners, with distal covering of very fine setae and setules. Left mandible (Figure 3B) incisor smooth with acute, blunted tip and distal margin roughness. Left lacinia mobilis (Figure 3C) broad, well-developed with four small distal processes and two strong adjacent pectinate setae. Right mandible (Figure 3D) incisor smooth with acute tip. Right lacinia mobilis (Figure $3 \mathrm{E})$ reduced, narrow, broadening distally with very fine denticulations along the distal margin and two adjacent pectinate setae. Mandibular molars strong, broad with corrugated striations on grinding surface. Labium (Figure 3F) inner lobes rounded, covered distally with fine setae and setules; anterior-facing surface also covered with sparser fine setae. Outer lobes distally setulose, each with a distally setulose, oval, articulated terminal process. Maxillule endite (Figures 3G, 3H, 3I) with eight terminal spiniform setae, three finely serrate and one more slender; attachment area surrounded by fine setae. Lateral margin of endite with sparse rows of short setae, stronger and denser in the middle half of the margin giving the appearance of fine serrations. Maxillule palp (Figure $3 \mathrm{G}$ ) slender, uniarticulate, tapering distally; damaged, carrying only three terminal setae in the illustrated specimen. Based on four other more successful dissections of this appendage, five or six terminal setae are expected. Maxilla (also Figure 3G) oval with a single long distal seta and very fine, minute setae on distal surface and distal third of medial surface. Maxil- 
liped (Figure 3J) coxae each with single long seta. Maxilliped bases not joined medially, each with three or four setae on medial margin - consisting of single shorter seta more proximal and two (to four) longer setae in proximal half of margin. Maxilliped basis with four or five (range: 3-6) setae in the distal half of the lateral margin, distally with row of four (sometimes five) long setae (decreasing in length towards lateral margin); anterior-facing surfaces covered with arcs of microtrichia. Maxilliped endite (Figures 3J, 3K) finely setulose, with sparse setae on distal lateral margin and surface; distally with two simple setae and mediodistally with two short spiniform setae (coupling hooks). Maxilliped palp with four articles of similar length. Article 1 length $1.1 \mathrm{x}$ width, medial and lateral margins with microtrichia arcs, giving impression of small serrations. Article 2 length $1.3 \mathrm{x}$ width, lateral margin with single distal seta, medial margin with row of five simple setae in distal half, and two stronger finely setulate setae in distal third. Article 3 length 1.8x width, with no lateral setae; medial margin with two parallel rows of setae - a row of ten (sometimes nine) stronger setae, very finely setulate on their distal two-thirds, and row of seven simple, shorter more slender setae (sometimes six). Article 4 length about three times width, with a single lateral marginal seta and two simple lateral subdistal setae (other palp with three lateral subdistal setae, one of them short but with no marginal seta; all other specimens dissected consistent with two lateral subdistal setae and single marginal seta). Palp article 4 medial margin with two parallel rows of setae on the distal third, one containing seven (range: 5-7) finely serrate setae and the other seven (sometimes six) simple setae [five finely serrate and seven simple setae visible on the other palp of illustrated specimen]. Epignath (Figure 3L) an elongate kidney shape with terminal circumplumose process, surface with only very fine, sparse setae.

Pereopod 1 (Figures 4A, 4B). Coxa with two setae (one very small), without anterior apophysis. Ischio-basis 3.7x as long as wide, $1.7 \mathrm{x}$ length of propodus, with dorsoproximal cluster of three short setae (two simple setae and one PSS) and one ventrodistal seta. Merus length $1.5 \mathrm{x}$ width, $0.6 \mathrm{x}$ as long as propodus, ventrodistally with two short setae, one medial and one lateral; dorsodistally with a single short seta. Carpus length $1.7 \mathrm{x}$ width, $0.7 \mathrm{x}$ as long as propodus, dorsal margin with two setae in distal half, ventrodistally with row of three setae. Propodus $3.2 \mathrm{x}$ as long as wide, $0.7 \mathrm{x}$ length of merus and carpus combined, 1.4x length of carpus, dorsal margin with short PSS and seta about two-thirds of way and single subdistal seta. Ventrally, propodus with a cluster of three setae subdistal and two (or one) shorter setae spaced in the distal third of the margin. Distal half of the ventral surface with microtrichia arcs. Dactylus and unguis combined shorter than propodus (x0.8), dactylus $1.3 \mathrm{x}$ length of unguis, with short dorsomarginal seta.

Pereopod 2 (Figures 4C, 4D, 4E). Coxa (not shown) with two setae, one very short. Ischio-basis length 2.8x width, 3.0x length of propodus, dorsoproximally with cluster of three setae (two PSS and one simple) about one quarter of way along and ventrodistally with three setae (very short, medium, and longer). Merus length $1.9 \mathrm{x}$ width, $1.5 \mathrm{x}$ as long as propodus. Merus with short medial seta and short lateral seta dorsodistally, ventrally with one mid-marginal seta plus sparse microtrichia in proximal half, with one short simple, one long simple and two crotchets ventrodistally; microtrichia in the distal fifth. Carpus length $1.1 \mathrm{x}$ width, $0.8 \mathrm{x}$ length of propodus. Carpus with single seta dorsodistally reaching four-fifths the length of the propodus, mediodistal margin with row of four crotchets and laterodistal margin with row of six crotchets, microtrichia in arcs towards ventrodistal end of article. The largest carpal crotchet with midlevel spines (Figure 4D). Propodus length 3.0x width, $0.7 \mathrm{x}$ length of merus. Propodus dorsally with single PSS in distal third, dorsodistally with longer seta and sparse microtrichia, ventrally with two (one in smaller females, three in the largest female) marginal setae, also with single distal seta; microtrichia visible towards the distal end of ventral surface. Dactylus and unguis combined $0.45 \mathrm{x}$ length of propodus and dactylus $2.8 \mathrm{x}$ length of unguis.

Pereopod 3 (Figure 4F). Similar in structure and ornamentation to pereopod 2 but overall slightly shorter. For completeness, ischio-basis length $2.4 \mathrm{x}$ width and $2.4 \mathrm{x}$ length of propodus, with dorsoproximal cluster of three short setae (one simple and two PSS) about one quarter of way down margin and three setae (short, medium, and long) ventrodistally. In contrast to pereopod 2, pereopod 3 with a single short PSS about two-thirds of way down ventral margin. Merus $1.7 x$ as long as wide, $1.4 x$ length of propodus, dorsodistally with only single short seta, ventrodistally with two crotchets and pair of unequal setae, ventromarginally with single seta about mid-point and microtrichia visible on proximal half and distal quarter. Carpus $1.3 \mathrm{x}$ as long as wide, $0.9 \mathrm{x}$ length of propodus, dorsodistally with pair of unequal setae, one very short (not seen on pereopod 2), the mediodistal margin with row of five crotchets, laterodistal margin with row of six crotchets, and microtrichia ventrodistally; the largest carpal crotchet with midlevel spines. Propodus length 3.3x width, shorter than merus $(0.7 \mathrm{x})$, dorsally with single PSS in distal third (other specimens also with additional small dorsodistal seta), and with sparse microtrichia at the distal end. Propodal ventral margin with two marginal setae, single distal seta, and microtrichia. Dactylus and unguis combined shorter than propodus (x0.4). Dactylus without setae, $2.9 \mathrm{x}$ as long as unguis. 


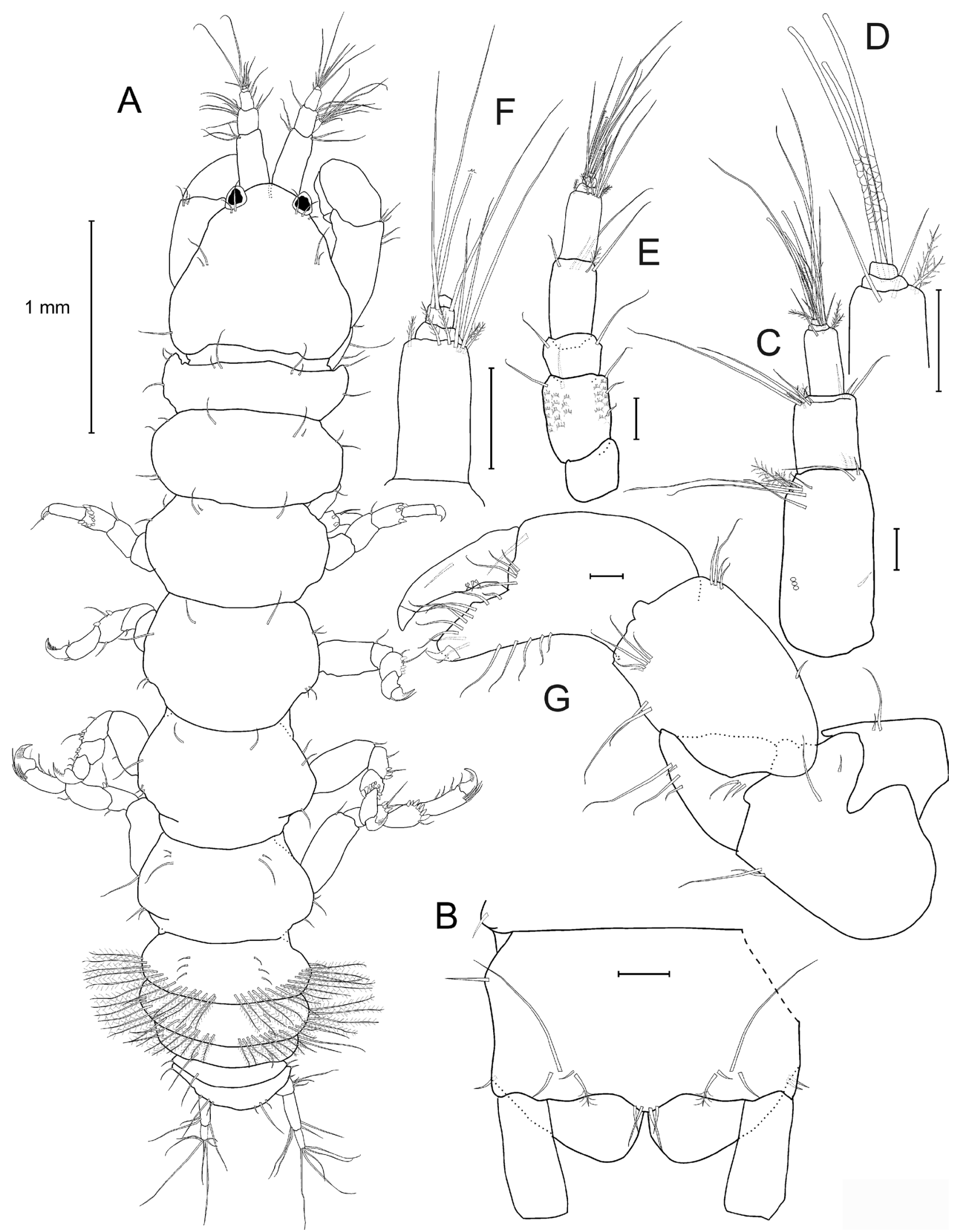

FIGURE 2. Tanais adelaidensis n. sp. (West Beach, Adelaide, February 2010). Female, holotype (SAMA Cat. No. C14331): A Full body (please refer to text and drawings of appendages for complete details of setation, ornamentation and somite measurements). Female, ovigerous, paratype (SAMA Cat. No. C14332): B Pleotelson (dashed line where folding of tissue obscured margin); C Antennule (small circles on first article show setal attachment sites); D Antennule distal articles (aesthetascs and setae distal on third article illustrated only); E Antenna; F Antenna distal articles (setae on fifth and seventh articles illustrated only); G Cheliped. Scale bars: A $1.0 \mathrm{~mm}, \mathrm{~B}-\mathrm{G} 0.1 \mathrm{~mm}$. 


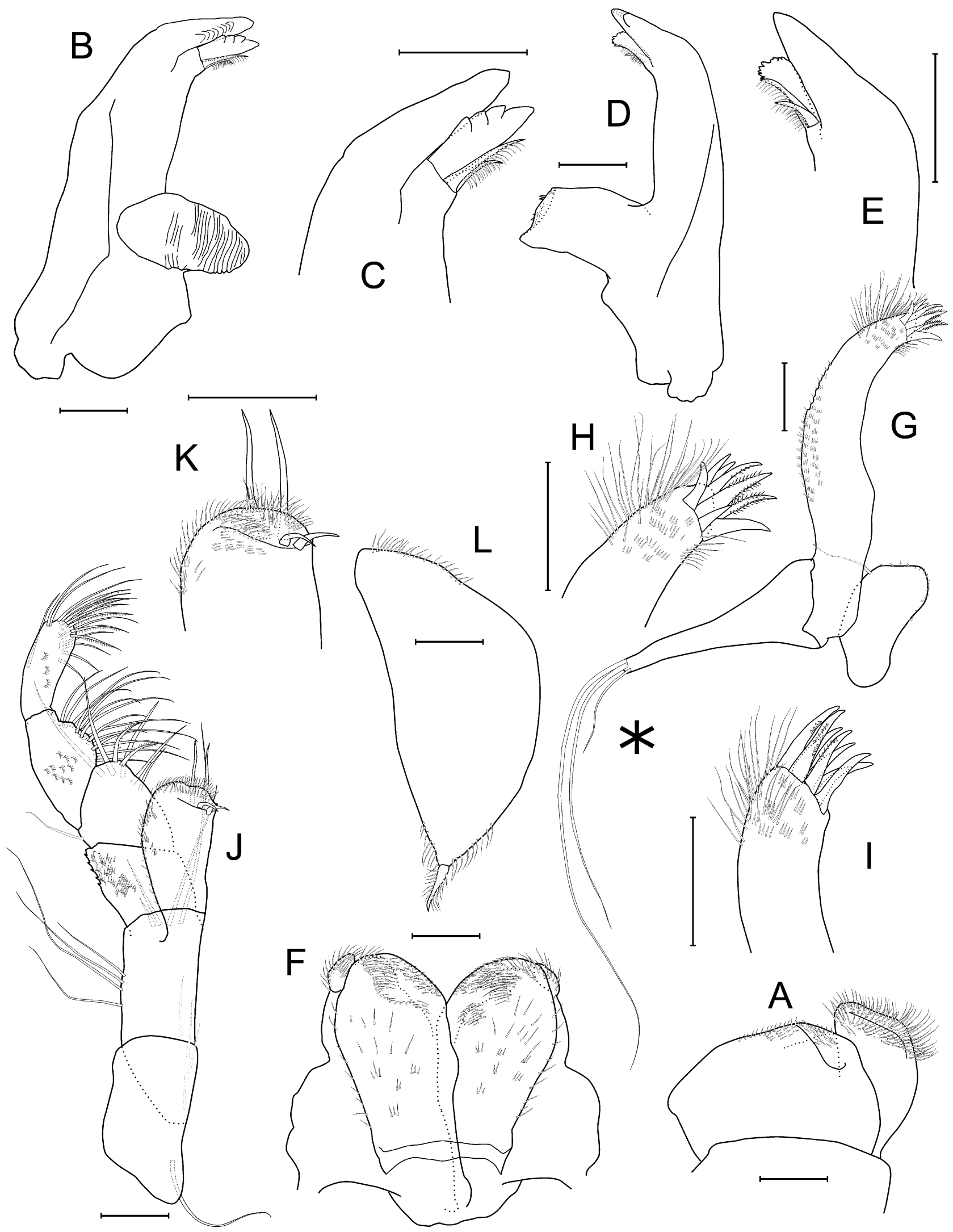

FIGURE 3. Tanais adelaidensis n. sp. (West Beach, Adelaide, February 2010). Female, ovigerous, paratype (SAMA Cat. No. C14332): A Labrum; B, C Left mandible; D, E Right mandible; F Labium; G Maxillule (see *) \& maxilla 2; H, I Maxillule endite tips; J Maxilliped with palp and endite; K Maxilliped endite detail; L Epignath. * Damage to terminal setae on the maxillule palp in this paratype during dissection. Based on four other more successful dissections of this appendage, five or six terminal setae are expected. Scale bars: $0.1 \mathrm{~mm}$. 


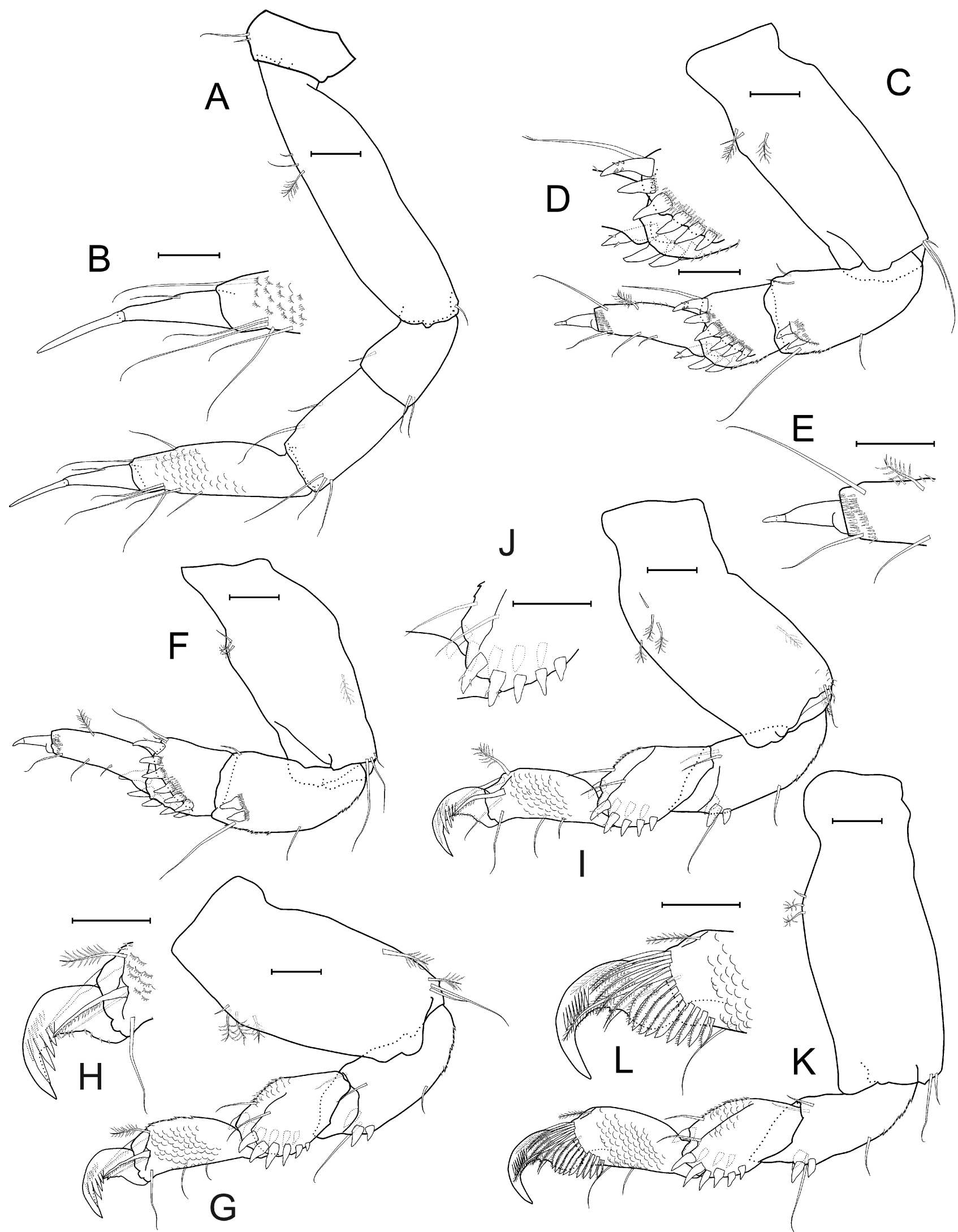

FIGURE 4. Tanais adelaidensis n. sp. (West Beach, Adelaide, February 2010). Female, ovigerous, paratype (SAMA Cat. No. C14332): A, B Pereopod 1; C, D, E Pereopod 2; F Pereopod 3; G, H Pereopod 4; I, J Pereopod 5; K, L Pereopod 6. Scale bars: $0.1 \mathrm{~mm}$. 
Pereopod 4 (Figures 4G, 4H). Ischio-basis length $2.1 \mathrm{x}$ width, twice length of propodus, slightly wider than ischio-basis on pereopods 2 and 3. Ischio-basis with dorsoproximal grouping of four setae (three in a cluster [one simple and two PSS] and an additional short PSS), a PSS about three-quarters of the way down the ventral margin, a subdistal shorter PSS, and pair of unequal ventrodistal setae. Merus length $2.1 \mathrm{x}$ width, $1.2 \mathrm{x}$ length of propodus. Merus with mid-margin ventral seta, microtrichia visible proximal to this, dorsodistally with single medial and lateral setae, ventrodistally with single lateral crotchet and pair of medial crotchets, single seta between them, and microtrichia in the distal region of the ventral margin (not shown). Carpus length $1.5 \mathrm{x}$ width, $0.9 \mathrm{x}$ length propodus. Carpus with row of six crotchets on mediodistal margin, row of six crotchets on laterodistal margin, dorsodistally with single medial and lateral setae, and microtrichia in attachment area of crotchets; largest crotchet with mid-level spines (not shown). Propodus length $2.6 \mathrm{x}$ width, slightly shorter than merus ( $0.8 \mathrm{x})$, with strong microtrichia arcs, scale-like, on distal two-thirds of medial and lateral dorsal surfaces. Propodus with single dorsodistal PSS, medial and lateral dorsodistal corners each with single long distally pinnate seta (finely setulate on one side in its distal half), single setae in both medial and lateral ventrodistal regions and two (three in the largest dissected female) setae on ventral margin. Dactylus and unguis fused to claw, with five or six spinules in lateral comb rows on medial and lateral surfaces and microserrations along proximal half of ventral edge of claw.

Pereopod 5 (Figures 4I, 4J). Similar to pereopod 4. For completeness, ischio-basis length 2.0x width, 1.9x length of propodus, slightly wider than ischio-basis on pereopods 2 and 3. Ischio-basis with dorsoproximal grouping of four setae (three in a cluster [one simple and two PSS] and an additional short PSS), a PSS about three-quarters of the way down the ventral margin, a subdistal shorter PSS, and pair of unequal ventrodistal setae. Merus length $2.2 \mathrm{x}$ width, 1.1x length of propodus. Merus with mid-margin ventral seta, microtrichia visible proximal to this, dorsodistally with single medial and lateral setae, ventrodistally with single lateral crotchet and pair of medial crotchets, single seta between them, and microtrichia in the distal region of the ventral margin (not illustrated). Carpus length $1.5 \mathrm{x}$ width, $0.9 \mathrm{x}$ length propodus. Carpus with row of five crotchets on mediodistal margin, row of five crotchets on laterodistal margin, dorsodistally with single medial and lateral setae, and microtrichia in attachment area of crotchets; largest crotchet with mid-level spines (Figure 4J). Propodus length $2.7 \mathrm{x}$ width, slightly shorter than merus $(0.9 \mathrm{x})$, with strong microtrichia arcs, scale-like, on distal two-thirds of medial and lateral dorsal surfaces. Propodus with single dorsodistal PSS, medial and lateral dorsodistal corners each with single long distally pinnate seta (finely setulate on one side in its distal half), single setae in both medial and lateral ventrodistal regions and two (three in the largest dissected female) setae on ventral margin. Dactylus and unguis fused to claw, with five or six spinules in lateral comb rows on medial and lateral surfaces and microserrations along proximal half of ventral edge of claw.

Pereopod 6 (Figures $4 \mathrm{~K}, 4 \mathrm{~L}$ ). Ischio-basis length $2.3 \mathrm{x}$ width, $2.4 \mathrm{x}$ as long as propodus. Ischio-basis with dorsoproximal grouping of setae (one simple, two PSS and possibly a fourth underneath), very short proximal seta towards ventral side, and sparse arcs of microtrichia plus pair of unequal setae ventrodistally. Merus length $2.3 \mathrm{x}$ width, $1.3 x$ length of propodus. Merus with single medial and lateral dorsodistal setae, ventrally with sparse microtrichia and single marginal seta, ventrodistally with three crotchets, two medial and one lateral, single seta between them and microtrichia around their base. Carpus length $1.5 \mathrm{x}$ width, similar length to propodus. Carpus with single medial and lateral dorsodistal setae, microtrichia arcs on dorsal surface, row of six crotchets on mediodistal margin and five on the laterodistal margin, largest carpal crotchet with mid-level spines as in pereopods 4 and 5 (not shown). Propodus length $2.0 \mathrm{x}$ width, $0.8 \mathrm{x}$ length of merus, with extensive microtrichia arcs, two (sometimes three) ventromarginal setae and single short dorsodistal PSS. Propodus with single long strong pinnate seta in lateral dorsodistal region and smaller seta attached in lateral ventrodistal region. Medially, propodus with single long strong pinnate seta mediodistal, row of five shorter biserrate setae (range: 4-6, size effect), and row of nine flat, leaf-like setae (range: 7-11; size effect) extending down to ventrodistal corner. Dactylus and unguis fused to strongly curved claw, with lateral comb rows of eleven fine spinules on medial surface and lateral surfaces, and microserrations along proximal half of ventral edge.

Pereopods 2 and 3 have two ventrodistal meral crotchets and pereopods 4 to 6 three ventrodistal meral crotchets in all dissected females, despite a body length range of 3.6-5.8 $\mathrm{mm}$. Total carpal crotchets on pereopod 2 varied little between female specimens ( 9 or 10; 4 medial and 5 or 6 lateral). On pereopod 3, total carpal crotchets showed a range of 9 to 13,13 (7 medial and 6 lateral) occurring in the largest dissected female $(5.8 \mathrm{~mm})$. Pereopods 4 to 6 had 10-12 distal carpal crotchets in the six dissected females. The number of propodal ventromarginal setae showed some evidence of a size effect. 


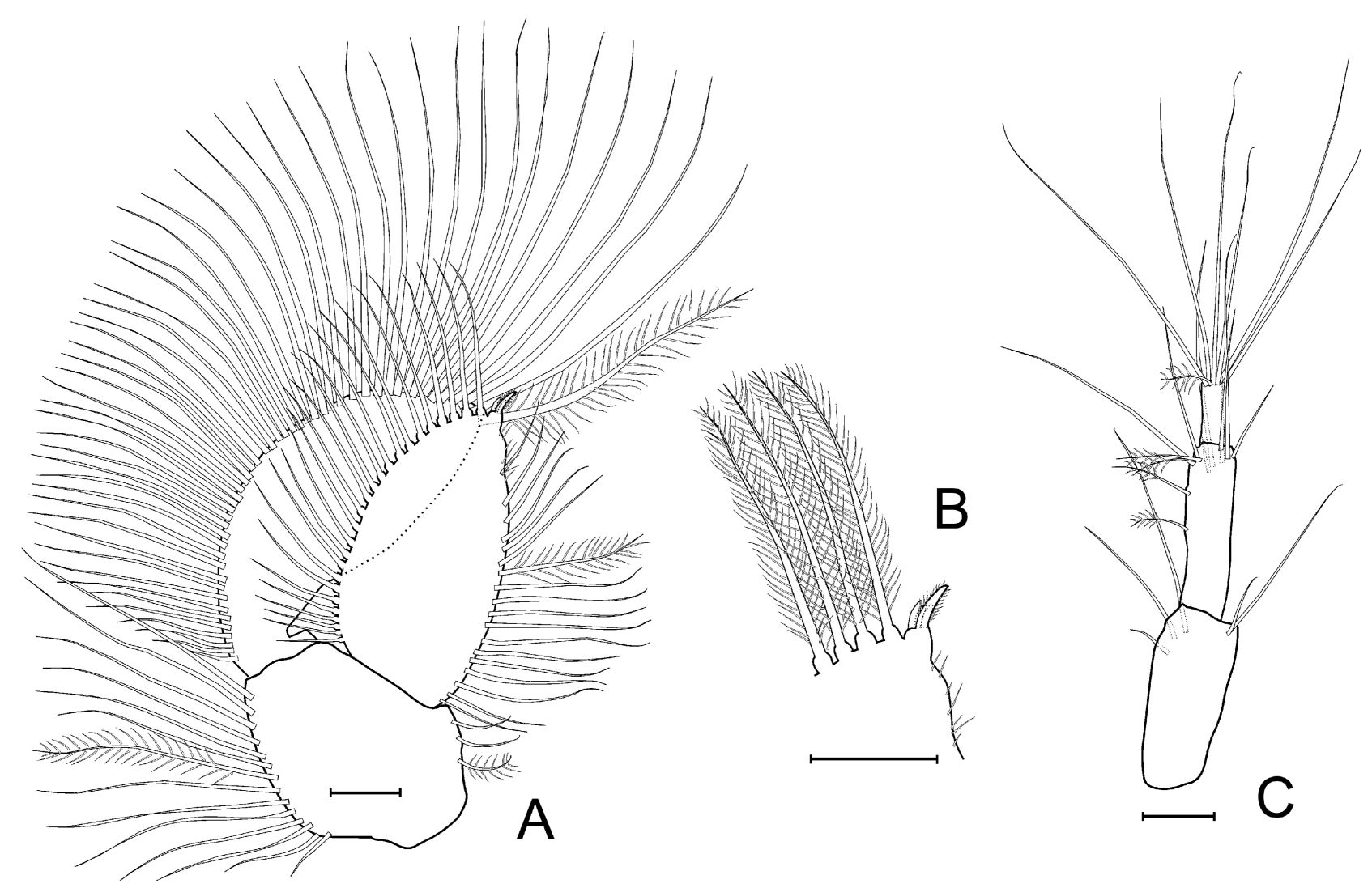

FIGURE 5. Tanais adelaidensis n. sp. (West Beach, Adelaide, February 2010). Female, ovigerous, paratype (SAMA Cat. No. C14332): A Pleopod 1; B Endopod distal end; C Uropod. Scale bars: $0.1 \mathrm{~mm}$.

Pleopods (Figures 5A, 5B). Three pairs of similar pleopods; pleopod 3 of same form but slightly smaller than first two pleopods (by about 15\% based on measurements of lengths and widths of articles) and with fewer plumose setae. Specimen size effect evident in numbers of plumose setae. Pleopod 1 basis with three short plumose setae on medial margin (range: 2-3) and 14 (range: 11-14) plumose setae on lateral margin. Exopods one-articled, medial margins with very fine sparse setae, lateral margins with about fifty plumose setae. Endopods one-articled, medial margins with 18 plumose setae (range: 15-21) and very fine, short setae on distal portion; lateral margin with 25 plumose setae in illustrated specimen plus a short, terminal seta consisting of three leaf-shaped structures (Figure 5B). Pleopod 2 as pleopod 1. Pleopod 3 basis with one (or two) medial plumose setae and ten (range: 7-10) lateral plumose setae, one of them very short. Endopod one-articled, medial margin with 12 plumose setae (range: 12-18) and very fine, short setae on distal portion; lateral margin with 21 plumose setae plus a short, terminal seta of same form as pleopods 1 and 2. Exopod one-articled with very fine sparse seta on medial margin and 45 plumose setae on lateral margin.

Uropods (Figure 5C). Uropod with three segments (including the basal segment or peduncle). Basal segment length $2.2 \mathrm{x}$ width, distally with three setae (small, medium, long) towards lateral side and pair of unequal setae towards medial side; sparse microtrichia visible distally. Second segment approaching $4.0 \mathrm{x}$ as long as wide, slightly longer than basal segment; with two short lateral marginal PSS, distally with two PSS, five simple setae of various lengths, and, towards medial side, three simple setae (short, medium, long). Third segment $0.4 \mathrm{x}$ basal segment length, about $2.5 \mathrm{x}$ as long as wide, with six simple setae and single short PSS terminally.

Description: MALE. Allotype full body, SAMA Cat. No. 14333; appendages from dissected paratype, SAMA Cat. No. 14334, partially dissected paratype, SAMA Cat. No. 14335 (Figures 6-7, Table 2.)

Male similar to female, but more compact, with weak sexual dimorphism in chelipeds, antennule and antennae. 


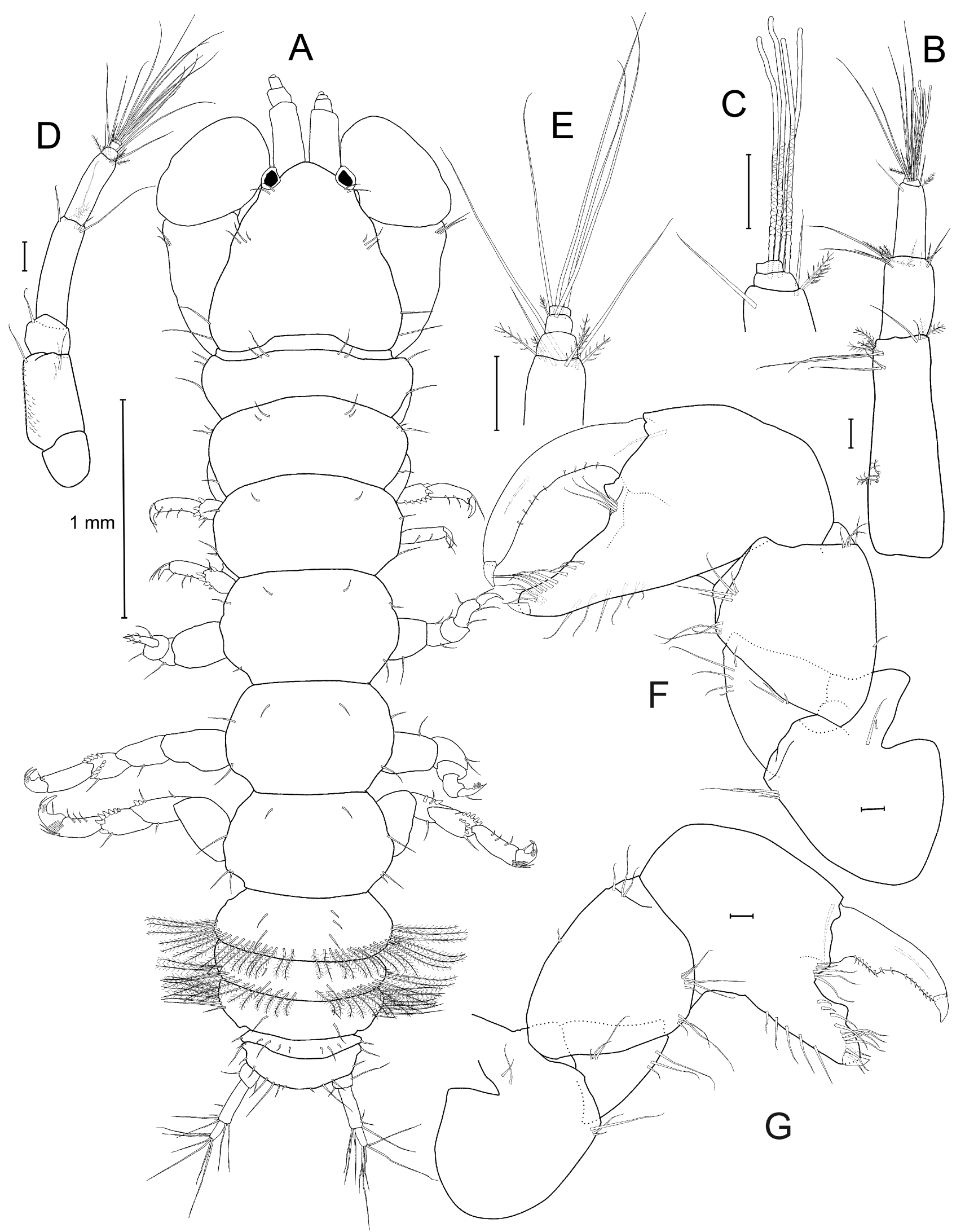

FIGURE 6. Tanais adelaidensis n. sp. (West Beach, Adelaide, February 2010). Male, allotype (SAMA Cat. No. C14333): A Full body (please refer to text and drawings of appendages for complete details of setation and ornamentation and somite measurements). Male, paratype (SAMA Cat. No. C14334): B Antennule; C Antennule distal articles (aesthetascs and setae distal on third article illustrated only); D Antenna; E Antenna distal articles (setae on fifth and seventh articles illustrated only); F Cheliped. Male, preparatory paratype (SAMA Cat. No. 14335): G Cheliped. Scale bars: A $1.0 \mathrm{~mm}$, B-G $0.1 \mathrm{~mm}$. 


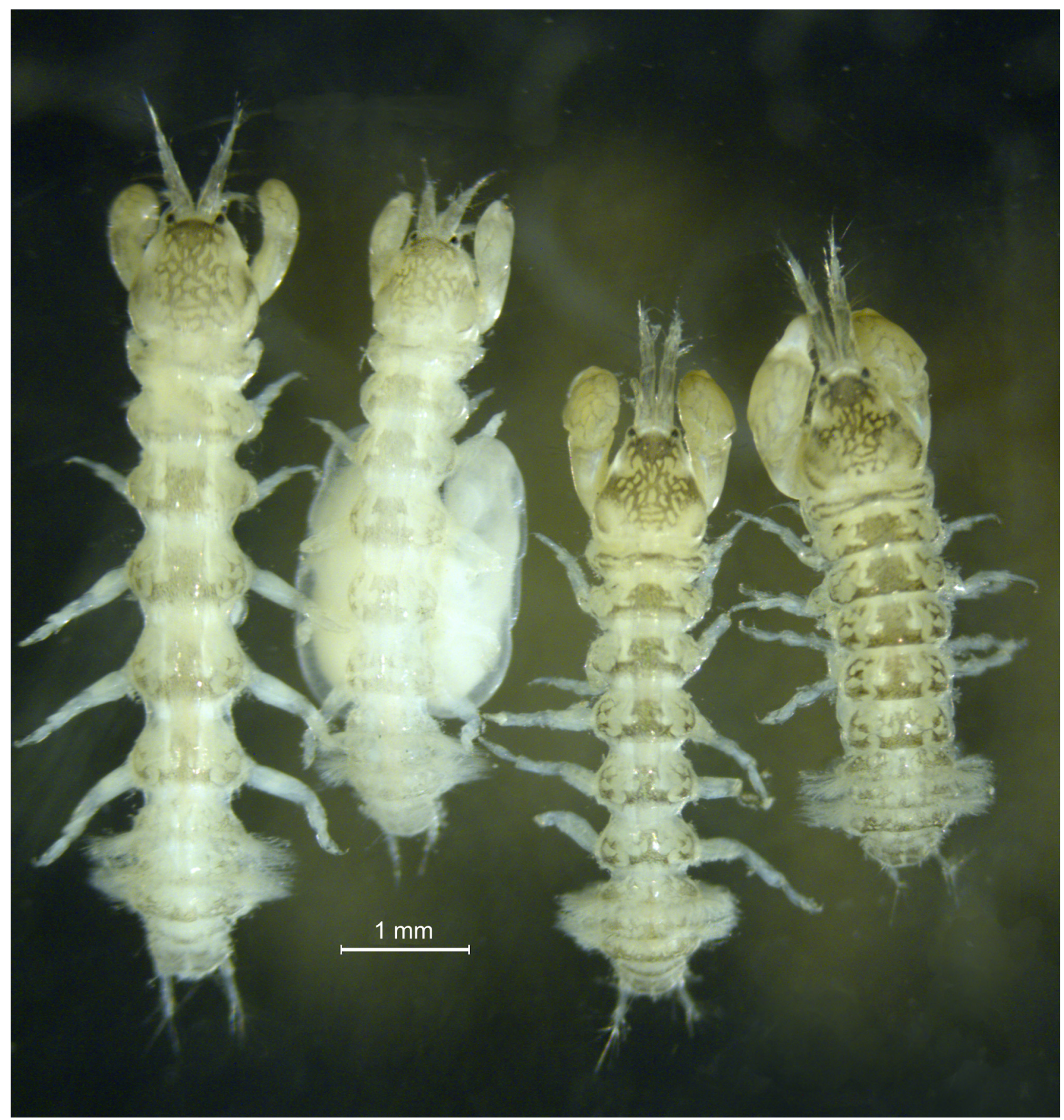

FIGURE 7. Tanais adelaidensis n. sp. (West Beach, Adelaide, February 2010). From left to right: preparatory female, ovigerous female, preparatory male, mature more dimorphic male.

Body (Figure 6A). Slightly stouter than female, 5.0x as long as maximum pereonal width. Cephalothorax a fifth of total specimen length, rounded anteriorly, length similar to width $(1.1 \mathrm{x})$ and $0.9 \mathrm{x}$ length of pereonites 1 to 3 combined. Setation as in female, with two or three setae in dorsolateral cluster about one-third of way from anterior end. Relative lengths of pereonites similar between male and female. Pereonite $10.5 x$ length of pereonite 4 , length $0.3 x$ width. Pereonite $20.8 x$ length of pereonite 4 , length $0.4 x$ width. Pereonite $30.9 x$ length of pereonite 4 , length $0.5 x$ width. Pereonite 4 length $0.6 x$ width. Pereonite 5 similar length to pereonite 4 , with length $0.6 x$ width. Pereonite 6 $0.9 x$ length of pereonite 4 , with length $0.6 x$ width. Pereonites 5 to 6 widen only slightly posteriorly. Pereonites 1 to $31.2 \mathrm{x}$ as long as maximum width. Pereonal setation and pleosome dimensions and setation similar to female. Males also showed variability in pereonite spread; younger males tending to be more extended and mature males more compact (Figure 7). Among 6 mature males, body lengths 3.9-4.9 mm, median (range) of body length to maximum 
pereonite width was 5.0 (4.8-5.2); ratio of cephalothorax length to combined length of first three pereonites 0.85 (0.81-0.86); cephalothorax $19.9 \%$ (19.1-20.3\%) of body length; ratio of combined length of pereonites 1 to 3 to maximum width 1.16 (1.15-1.23); and pleon $25.1 \%$ (24.4-26.4\%) of body length.

Antennule (Figures 6B, 6C). Antennule with five articles, relatively longer than cephalothorax compared with female (1.1x cf. $0.8 \mathrm{x})$. Relative lengths of articles similar between sexes, but male articles slightly more elongate. Setation and ornamentation similar, minor differences; tendency for an additional aesthetasc in males compared with females. For completeness, first article longer than second article (2.6x), more elongate than in female (2.9x as long as wide $c f .2 .1 \mathrm{x}$ ), with cluster of three short dorsolateral PSS in proximal half. Distally, first article with four dorsolateral setae (two of these subdistal), row of four short PSS in ventrolateral region, two PSS ventromedially, and pair of unequal simple setae dorsomedially (range: 6-7 subdistal/distal simple setae, 3-6 distal PSS). With reference to other antennule mounted for this specimen and other specimens, antennule first article also has two or three setae on medial margin. Second article $1.6 \mathrm{x}$ as long as wide, $0.4 \mathrm{x}$ as long as first article. Distally, second article with four unequal setae in row extending dorsolateral to lateral, row of four PSS in ventrolateral region, single ventral PSS, and pair of shorter simple setae ventromedial and dorsomedial. Second article with total of eight simple setae and five PSS (range: 6-8 simple, 4-5 PSS) distally. Third article only slightly shorter than second article (0.9x), 2.4x as long as wide, distally with simple medium length dorsolateral seta, single shorter ventromedial seta, and two short medial PSS (Figure 6C). Fourth and fifth articles very short (Figure 6C; only aesthetascs and setae distal on third article shown). Fourth article with four simple setae attached in dorsal region (range: 3-5) and three (range: 2-4) aesthetascs attached ventrally. Fifth article also short, with smaller diameter than fourth article, with short PSS, one (or two) aesthetasc(s), and five terminal setae (range: 4-6), one of these very short. Fourth and fifth articles together with seven longer simple setae plus three shorter, fine setae (range: 8-10, total simple setae), one short PSS, and four (range: 4-6) aesthetascs distally.

Antenna (Figures 6D, 6E). Antenna as long as antennule, with eight articles. Relative lengths of antennal articles similar between sexes, but articles more elongate in male, particularly articles 2, 4 and 5. First article length similar to width, without setae. Second article $2.5 \mathrm{x}$ as long as third article, length $1.7 \mathrm{x}$ width, with extensive microtrichia arcs. Second article with one short ventromarginal seta, distally with three setae (one ventral, one dorsomedial, and one dorsolateral). Third article $0.4 \mathrm{x}$ length of second article, $0.9 \mathrm{x}$ as long as wide; distally with single simple dorsal seta, also with microtrichia arcs on dorsal surface (not shown). Fourth article 1.2x length of second article, length $3.8 \mathrm{x}$ width; distally with one long ventral simple seta, one ventral PSS, pair of unequal simple dorsolateral setae, and single medium length dorsomedial seta (total setae distally: 4 simple, 1 PSS; range: 3-4 simple, 1PSS). Fifth article $3.3 \mathrm{x}$ as long as wide, $0.8 \mathrm{x}$ length of second article; distally with three simple setae attached ventrally and five short PSS, two attached ventromedially, two ventrolaterally, and one dorsolaterally (Figure 6E) (range: 3 simple (5 in one specimen of six), 2-5 PSS). Sixth, seventh, and eighth articles very short (Figure 6E; only setae on fifth and seventh articles shown). Sixth article very short, half as long as wide, only $0.1 \mathrm{x}$ length of second article, with four simple distal setae (range: 2-4), one pair attached dorsolaterally, the other shorter pair in the ventromedial region. Seventh article also very short, half as long as wide, with four long distal setae, three attached ventrally, the other dorsally, and single short PSS. Eighth article tiny, half as long as wide, with five longer terminal setae. Seventh and eighth articles with total of nine distal setae (range: 8-9) and single short PSS.

Mouthparts. As in female, with minor differences in setation as follows. Maxillule palp slender, tapering distally, with (at least) four terminal setae (five to seven setae were observed in other dissections, finely setulate in their distal halves). Maxilliped bases each with four (or three) setae on the medial margin, a shorter seta proximal and three (or two) longer setae regularly spaced along the proximal half of margin. Each maxilliped basis with distal row of five (or four) long setae, increasing in length lateral to medial, and six lateral setae (four long and two shorter; range: 4-6). The maxilliped palp article 3 medial margin with two rows of setae - a row of nine (range: 8-10) stronger setae along central bulge and parallel row of six (range: 5-7) simple slender setae. Article 4 length about three times width, similar length to article 2, with single lateral seta and two simple subdistal setae. Article 4 medial margin with two parallel rows of setae on distal third, one containing six or seven slender simple setae and other with six or seven finely serrate setae.

Cheliped (Figure 6F). Cheliped larger than in female with notably arcuate, slender dactylus and fixed finger with different form. Basis relative dimensions and setation as in female, except for three or four rather than two or three unequal ventrodistal setae. Merus shape, dimensions and setation as in female, with five (sometimes four) setae ventrally. Carpus length notably shorter than propodus length $(C(L): P(L)=0.6$; range: $0.6-0.75)$, carpus length 


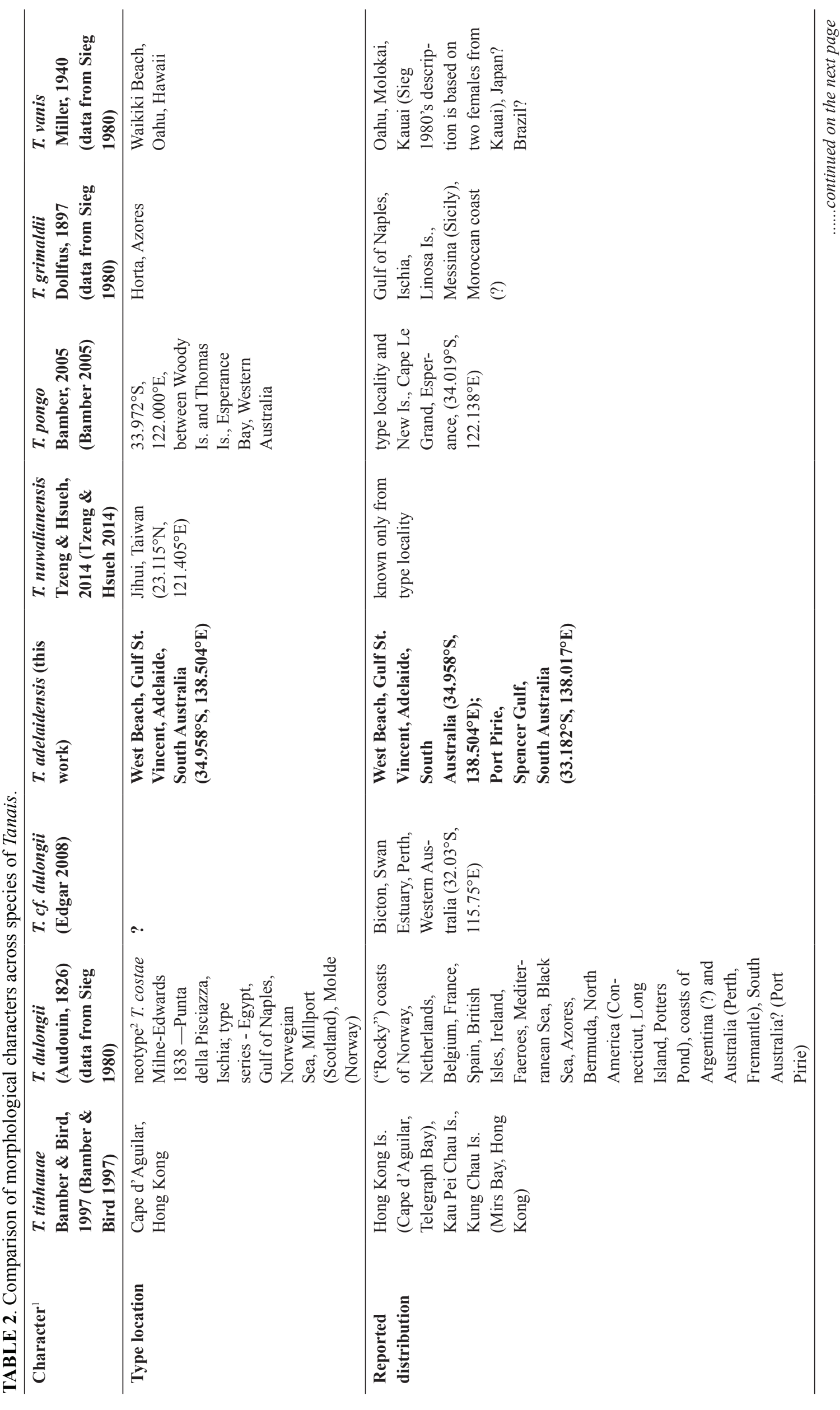

WEST BEACH TANAIDIDAE

Zootaxa 4996 (1) (C) 2021 Magnolia Press · 99 


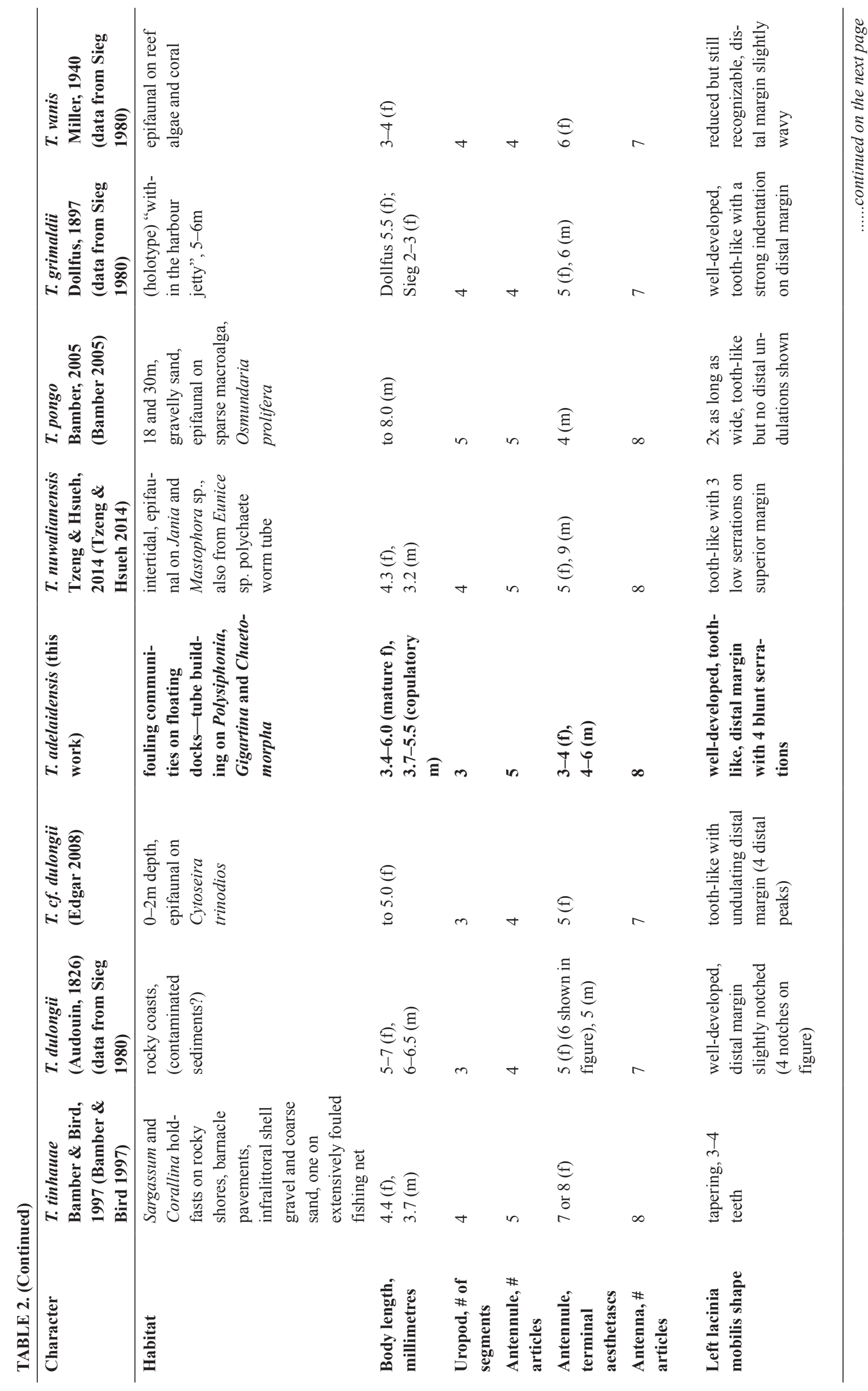




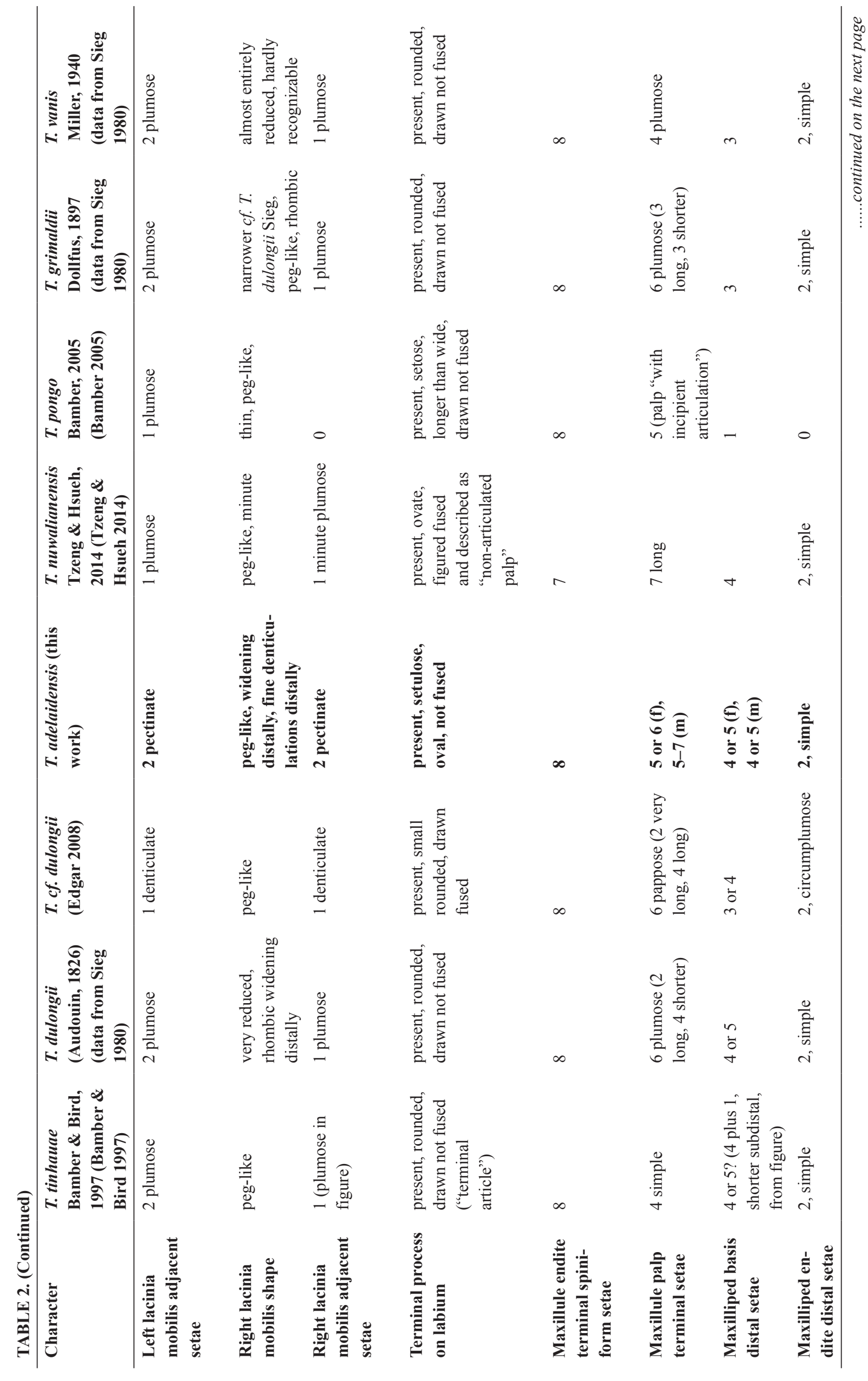

WEST BEACH TANAIDIDAE

Zootaxa 4996 (1) (C) 2021 Magnolia Press · 101 


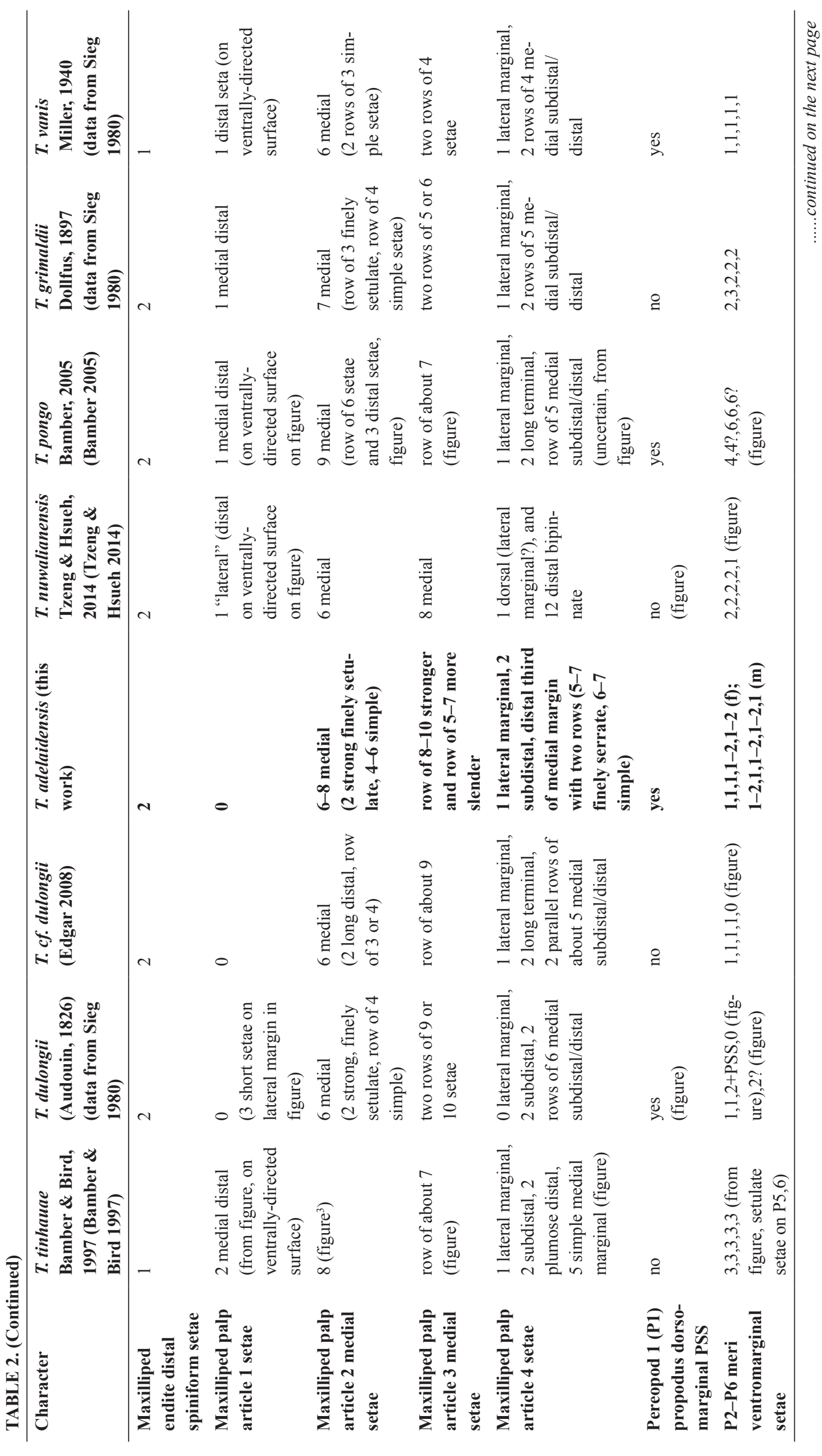




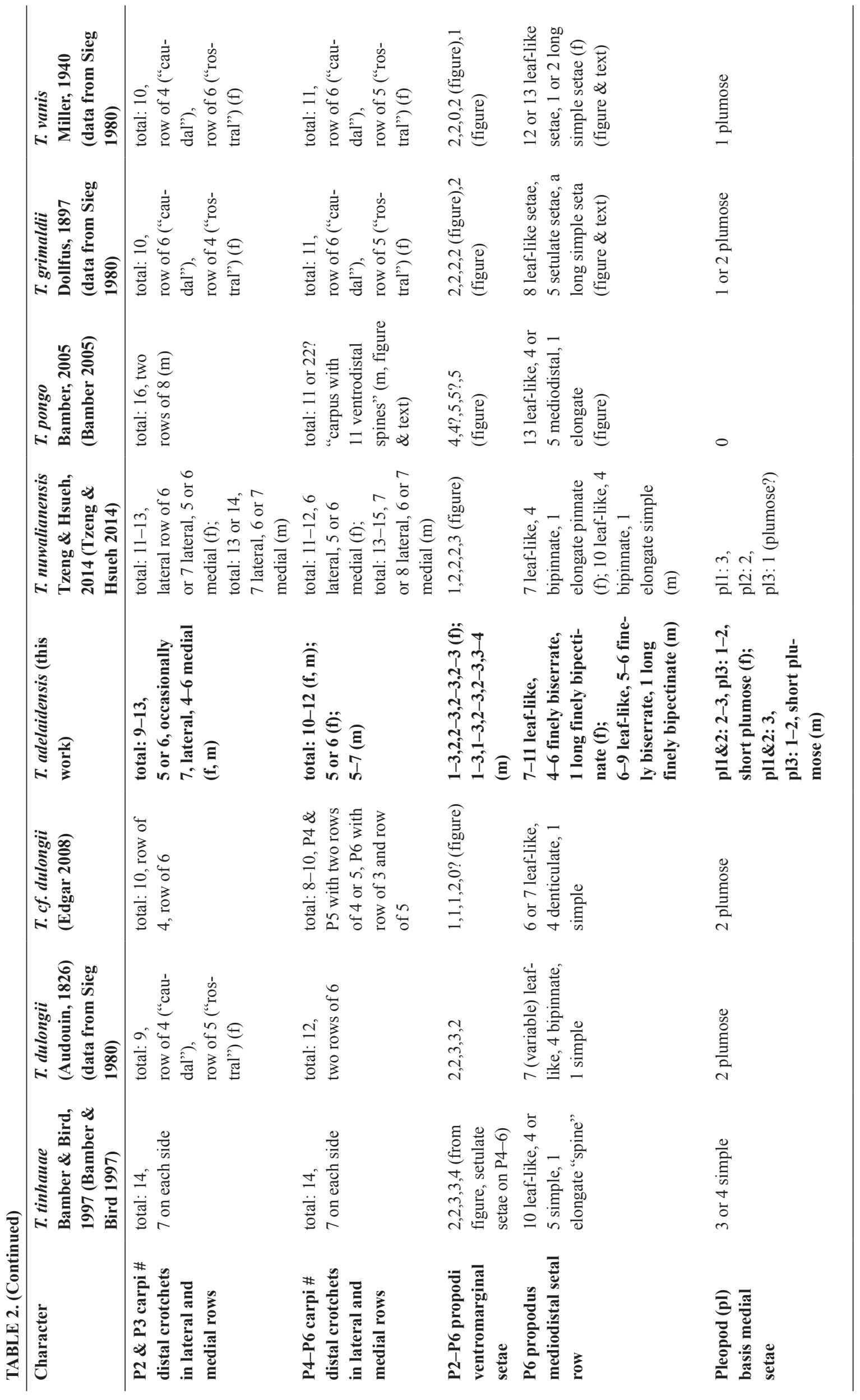




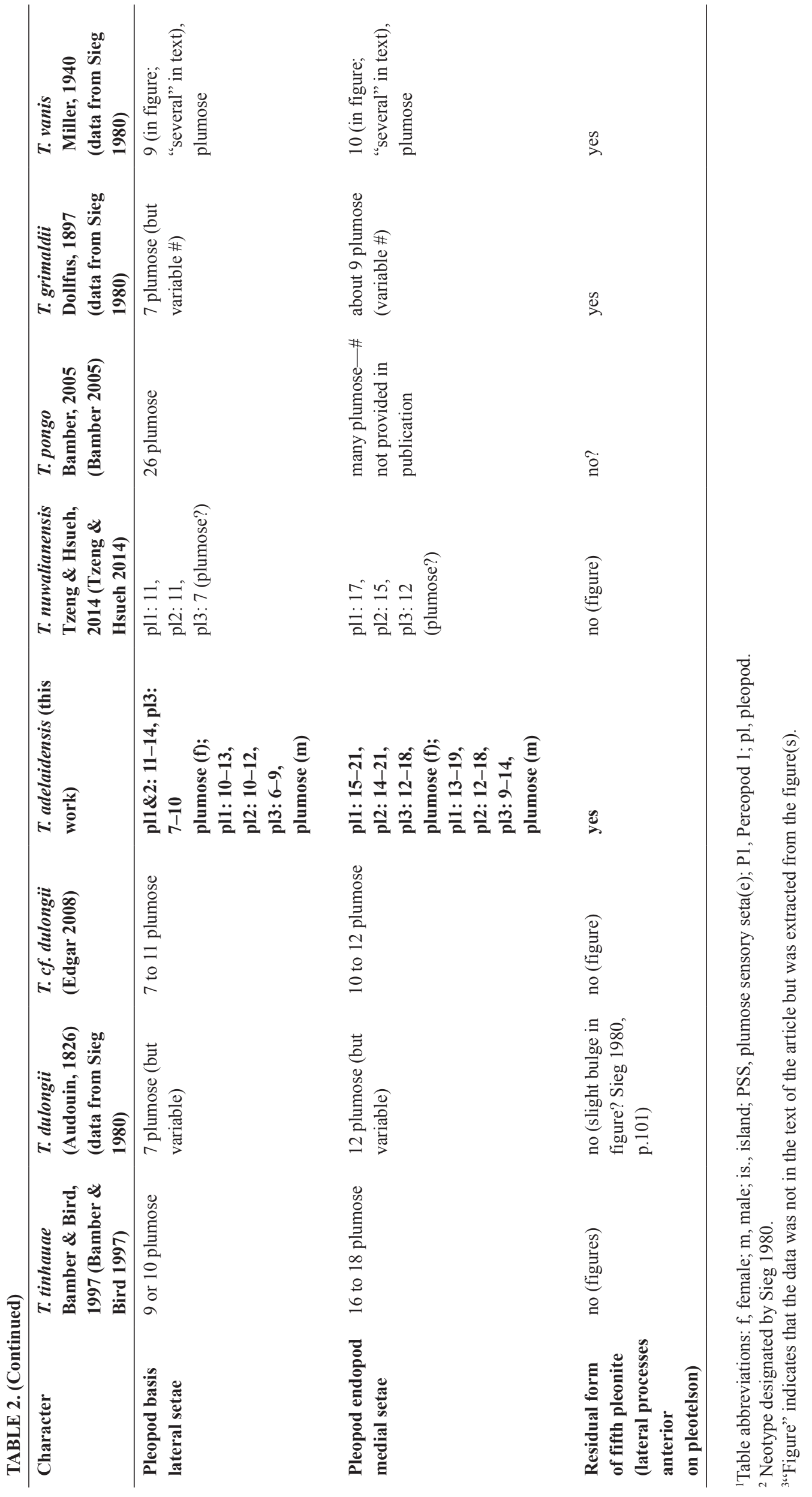


$1.2 \mathrm{x}$ width (range: $1.2-1.4$ ), otherwise of form similar to female. Setation similar to female with three ventral setae and four or five setae in row on distoventral region of lateral surface. Propodus of similar relative dimensions to female, about twice as long as wide (length including the fixed finger) with cluster of four or five setae at proximal end of fixed finger cutting edge close to junction with dactylus. Fixed finger form differs from female - narrow, with a smooth cutting edge and no mid-edge process, but with small triangular process close to articulation with dactylus; with six (range: 5-6) ventral setae, also with nine (range: 7-9) lateral dorsal setae in row attached just below cutting edge, and two medial setae close to terminal claw. Dactylus arcuate, smooth, similar length to fixed finger, with medial seta, a terminal claw, and ventrally with sparse row of small setules.

Cheliped (preparatory male, Figure 6G). Cheliped with less arcuate dactylus, appendage more similar in form to female but larger. Basis and merus with relative dimensions and setation as in female. Carpus shorter than propodus $(C(L): P(L)=0.75)$, length $1.3 x$ width, setation as in female with three rather than two setae ventrally. Propodus about twice as long as wide (length including the fixed finger). Setation and fixed finger form similar to female. Fixed finger cutting edge rounded distally, smooth with blunt triangular process mid-way, with cluster of five (four or five) setae at proximal end close to junction with dactylus. Fixed finger with five (four or five) ventral setae, dorsally with nine (seven to nine) lateral setae in row attached just below cutting edge, and two medial setae close to terminal claw. Dactylus not arcuate, as long as fixed finger, with terminal claw, ventrally with row of small setules, single medial seta, and obtuse triangular process about mid-margin.

Pereopods. Pereopod 1 coxa and articles similar to those in female with the following differences. Pereopod 1 overall more slender but relative lengths of articles consistent between sexes. Pereopod 2 in male similar to female with the following minor differences in ornamentation: merus sometimes with three rather than two simple crotchets ventrodistally; carpus with pair rather than single seta dorsodistally; and propodus sometimes with three rather than two ventromarginal setae. Pereopod 3 similar to that in female. Merus more commonly with three short, simple crotchets ventrodistally compared with two in the females. Pereopods 4 and 5 similar to each other and similar in males and females with the following differences in setation between sexes: ischio-basis sometimes with three rather than two simple unequal ventrodistal setae; merus sometimes with four rather than three ventrodistal crotchets.

Pereopod 6 similar to female with small differences in setation as follows: ischio-basis with dorsoproximal grouping of as many as five rather than four setae; merus with single mid-margin seta ventrally and consistently with three crotchets ventrodistally, unlike pereopods 4 and 5, but as in female; propodus with as many as four, but usually three, ventromarginal setae. Distomedial setal row on propodus with eight or nine flattened setae (six on one specimen) and five or six serrate setae.

Pleopods. Pleopods similar to each other, but pleopod 3 with slightly reduced setation. Pleopod 1 basis with three short plumose setae on medial margin and 12 (range: 10-13) plumose setae on lateral margin. Exopods one-articled with very fine sparse setae on medial margin and approaching fifty plumose setae on lateral margin. Endopods one-articled, medial margin with 17 (range: 13-19) plumose setae, distally with very fine, short setae, and lateral margin with around twenty plumose setae plus one stout, leaf-like terminal seta, similar to female. In one specimen on one pleopod, two of these terminal setae were present; this is likely an aberration. Pleopod 2 basis with three medial and 10-12 lateral plumose setae; endopod with 12-18 medial plumose setae. Pleopod 3 basis with only one or two medial plumose setae and 7-9 lateral plumose setae; endopod with 9-14 plumose setae.

Uropods. Uropods with three segments including basal segment (peduncle), as in female with respect to setation and relative lengths.

Comparison between January 2015 specimens and February 2010 time-series specimens. The single sampling in January 2015 contained specimens towards the smaller end of the size range of mature specimens observed in 5 samples from February in the time-series. In the January 2015 sampling, mature females ranged from 3.6-3.8 $\mathrm{mm}$ and mature males from 3.0-3.4 mm compared with 3.4-6.0 $\mathrm{mm}$ in females and 3.7-5.5 $\mathrm{mm}$ in males from the February 2010 time-series subset. We did not observe consistent morphological differences between dissected Tanais specimens collected in February 2010 and those from January 2015. Numbers of uropodal segments and antennal articles agreed as did the numbers of antennule aesthetascs and the presence of anterolateral processes on the pleotelson suggestive of a residual pleonite 5. Setation and form of mouthparts were consistent including laciniae mobiles and adjacent setae, distal ornamentation on the maxilliped endites, the absence of setae on the maxilliped palp first article and the single seta lateral on the second article. There was variability in the number of setae lateral (range: 3-6) and distal (range: 4-5) on the maxilliped basis and on the number of setae ventral on the propodi of pereopods 2 to 6 (range: $1-4$ ) suggestive of an effect from specimen size. 


\section{Remarks}

There are currently nine Tanais species in the WoRMS database (WoRMS 2021), excluding those that are designated nomen nudum. Table 2 contains morphological characters for those species with sufficient information in the published literature to extract these data. The West Beach Tanais specimens with their three-segmented uropods show the most affinity to the neotype T. dulongii collected in the Gulf of Naples, designated and described in Sieg (1980), and to T. cf. dulongii as described by Edgar (2008) (Table 2). Sieg (1980) also examined specimens from the western Mediterranean, several sites around the United Kingdom, the Netherlands, and two sites on the coast of eastern North America. Edgar's specimens were from Bicton, Swan Estuary, Western Australia, the same location where Thomson (1944) reported T. dulongii. All three species also agree in their lack of setae distal on the medial margin of maxilliped palp article 1. The West Beach specimens differ from the Sieg (1980) and Edgar (2008) descriptions with respect to: the number of articles in the antennule (5 versus 4$)$ and antenna ( 8 versus 7 ), the number of terminal aesthetascs in females ( 3 or 4 versus 5 or 6 ), the number of accessory setae adjacent to the right mandible lacinia mobilis ( 2 versus 1 ; consistent in all dissected specimens from West Beach), and a slight reduction in pleopod 3 relative to pleopods 1 and 2. The West Beach specimens also have anterolateral processes on the pleotelson, suggestive of a residual pleonite 5, more similar to T. grimaldii Dollfus, 1897. The anterolateral swellings on the pleotelson were easily mistaken for a fifth pleonite when specimens were viewed dorsally but examination from a lateral perspective showed clearly the existence of only four pleonites. Slide-mounted pleotelsons showed that there was no indication of actual segmentation near the margins as shown for T. vanis Miller, 1940 in Sieg (1980). The prominence of the anterolateral processes when viewed in this manner was influenced by any folding or overlapping of the tissue during mounting. The West Beach specimens differ from T. cf. dulongii in Edgar (2008) additionally with respect to the number of setae adjacent to the left lacinia mobilis (2 versus 1 ) and the nature of the long setae distal on the maxilliped endites (simple versus circumplumose). Considering the right lacinia mobilis, the shape found in the West Beach specimens is relatively narrow but long, more similar to that shown for T. grimaldii than T. dulongii in Sieg (1980). The three descriptions overlap with respect to the content of the mediodistal setal row on the propodus of pereopod 6 , the number of setae lateral on the maxilliped basis, the number of mediomarginal setae on the maxilliped basis, and the number of ventral setae on the cheliped merus.

The West Beach specimens exhibited a range of sizes among mature individuals. Mature females (ovigerous or with scars from ovisacs) ranged in size from $3.4-6.0 \mathrm{~mm}$ in the February samples examined in more detail. A female $7.5 \mathrm{~mm}$ long was found in a sample collected in October. The smallest female (sex determined by the presence of minute ovisac buds) was $1.8 \mathrm{~mm}$. Rumbold et al. (2012) reported size dimorphism associated with two recruitment periods in groups of $T$. dulongii in lifecycle and population dynamics studies at La Estafeta near Mar del Plata, Argentina. The authors proposed the following scenario to explain their results: a first group was composed of individuals recruited in the summer and early autumn that grew quickly and matured at a reduced size, continuing until July and August; a second group was recruited in late autumn, even winter, and survived the cold months growing the following spring, maturing at larger sizes, reproducing and disappearing in the summer. Females in their samples had a mean size of $4.18 \pm 0.77 \mathrm{~mm}$, the smallest female exhibiting sexual differentiation measuring $1.77 \mathrm{~mm}$ and the largest mature female $7.28 \mathrm{~mm}$. No intersex individuals were observed in the subset of West Beach samples used for size measurements. Rumbold et al. (2015b) described intersex T. dulongii at a site on the northern coast of Argentina with low human impact. No intersex individuals were observed at a nearby polluted harbour (Rumbold et al. 2014, 2015a). Further work-up of the times-series samples is required to determine the existence of any cohort effects on specimen size and whether intersex individuals are present in other samples not examined in as much detail.

We also found Tanais specimens at Port Pirie boat ramp in Spencer Gulf (Figure 1) which we consider not morphologically distinguishable from those at West Beach. Hutchings et al. (1993) and Ward \& Hutchings (1996) reported established populations of a Tanais species they identified as $T$. dulongii in heavy metal-contaminated intertidal sediments around Port Pirie. According to Wiltshire et al. (2010), a lack of preserved specimens, and also molecular data, precluded confirmation of their identification and thus any validation at that time of status as an introduced species. The specimens we have described in this paper were collected from macroalgal holdfasts on man-made floating structures rather than from contaminated sediments. It cannot therefore be concluded that the specimens that we have described are the same species as those collected by Hutchings and others in the 1990's.

The West Beach Tanais COl data differ only $2 \%$ from the genetic sequence obtained from specimens identified as T. dulongii collected at Dania Beach, Florida (Drumm 2010). A morphological description of Drumm's specimens has not been published. Morphological descriptions were also not published for specimens designated $T$. 
dulongii that were collected from Mindelo, Portugal, and Helgoland, Germany, the sources of the shorter but more genetically distant $C O 1$ sequences published by Larsen et al. (2014). Both the European populations were identified as $T$. dulongii, yet their genetic distance based on $\mathrm{CO}$ suggests that they are distinct.

Based on the combination of the morphological differences between the West Beach specimens and the published description of the T. dulongii neotype (Sieg 1980) as outlined in the first paragraph of this section, a new species designation is proposed for the West Beach specimens, Tanais adelaidensis. Further examination of this new species designation awaits a comprehensive phylogenetic study of the Tanais genus involving both morphological and, critically, molecular data encompassing specimens from different geographic locations, an endeavour outside the scope of the present study.

\section{Taxonomy—Hexapleomera Dudich, 1931}

\section{Molecular data}

Six West Beach Hexapleomera specimen isolates were amplified and sequenced - two sexually dimorphic males, two preparatory males, and two mature females. The sequences were identical, with the exception of one which differed by one nucleotide. The sequences for three of the specimens were submitted to GenBank, two of which were identical (655 nt; GenBank Accession Nos. MW980882, MW980883) and the sequence that differed by one nucleotide (655 nt; GenBank Accession No. MW980884).

The West Beach CO1 sequence matches that for Hexapleomera sasuke Tanabe \& Kakui, 2019 over the $655 \mathrm{nt}$ length published for that species (GenBank Accession No. LC474857.1). There is also agreement with the shorter 389 nt length published by Larsen et al. (2014) for Zeuxo turkensis Larsen, 2014 (GenBank Accession No. KF928323.1).

\section{Morphology}

Specimens examined were collected by K. Conlan within Gigartina macroalgae attached to the West Beach Boat Ramp, $34.958^{\circ} \mathrm{S}, 138.504^{\circ} \mathrm{E}$, on 29 March 2010 , and by R. Baring and T. Ramsdale at the same location in January 2015. Representative series (SAMA Cat. Nos. C14336-C14340) and the complete time series will be deposited at the South Australian Museum. Dissections were done from both the January 2015 single sampling (two females, 2.77 and 2.88mm; three males; 2.05, 2.19, and $2.31 \mathrm{~mm}$ ) and March 2010 Gigartina samples from the time-series (seven females, 2.54-4.33 mm; five males, 2.49-3.28 mm). We found no consistent differences in detailed morphology between these two sampling times despite the presence of a wider range of sizes of mature specimens in the more extensive March 2010 sampling. Four samples from March 2010 used to look further at specimen size had mature females (ovigerous or post-ovigerous) $2.2-4.3 \mathrm{~mm}(\mathrm{n}=111)$. Males with a clearly separate proximal dorsal "tooth" on the fixed finger and penile cones with gonadal pores were 2.1-3.3 $\mathrm{mm}(\mathrm{n}=23)$. The ratio of mature females to these males in the four samples ranged from 3.1 to 6.5. Considering all specimens with visible sexual differentiation, the female to male ratio was 2.4 to 4.2. Four intersex specimens were found in these four samples. These specimens had developing ovisacs, visible gonadal pores ventral on pereonite 6 , and cheliped fixed finger cutting edges with two triangular processes similar to preparatory males.

The morphology of the West Beach specimens agreed well with the detailed drawings and descriptions of $H$. sasuke in Tanabe \& Kakui (2019), including the presence of notable pigmentation on the pleopod rami. The specimens are clearly $H$. sasuke. We noted more setae posterior on the pleotelson in the West Beach specimens than reported for $H$. sasuke, including two pairs of apical setae rather than one and a pair of posterodorsal PSS, one each side of the central apex of the pleotelson, similar to those reported in Z. turkensis (Larsen 2014). Tanabe \& Kakui (2019) reported that the pleotelson was $0.75 \mathrm{x}$ as long as wide and longer than pleonite 1 in both males and females (ca. 1.2x from the figures in the publication), as also reported for Z. turkensis. We assessed the pleotelson as $0.6 \mathrm{x}$ as long as wide (median, range: $0.57,0.49-0.64$, mature females, $\mathrm{n}=9$; median, range: $0.57,0.52-0.64$, mature males, $\mathrm{n}=5$ ) and similar in length to pleonite 1 (median, range: $0.99,0.93-1.11$, mature females, $\mathrm{n}=9$; median, range: 1.06 , $0.95-1.19$, mature males, $\mathrm{n}=5$ ). This difference may have a systematic component due to, for example, the specific locations used for making measurements and a random component from slight variations in specimen orientation within the depth of field and judging beginning and ends of the somites. We also assessed a seventh article as present on antennae in the West Beach specimens. This and other differences are discussed further in the sections below. We ascribe them to specimen size effects, characters with subjectivity or judgement in their assessment and therefore 
prone to inter-operator differences, and in some cases, with challenges in obtaining clear views on slide mounts.

Since the West Beach CO1 molecular data were identical to the shorter $389 \mathrm{nt}$ partial sequence for Z. turkensis (Larsen et al. 2014), we also compared our information with its published description (Larsen 2014). The West Beach specimens differ from $Z$. turkensis with respect to the pleotelson length relative to pleonite 1 (similar lengths in our assessment, longer than pleonite 1 in Z. turkensis), the number of terminal setae on the antennule and antenna (antennule with seven to ten in the West Beach specimens versus three in Z. turkensis; antenna with 10 to 13 terminal setae in the West Beach specimens versus three in Z. turkensis), and the antenna article 3 setation (naked in West Beach males and females versus a single distal seta in the Z. turkensis male). Considering the mouthparts, the setae adjacent to the lacinia mobilis were pectinate in the West Beach specimens versus simple in Z. turkensis, proximal spines on the lower part of the labrum were absent versus present (although it is possible that position of the mounted part might be critical for whether these can be seen), the number of distal or subdistal spiniform setae on the maxilliped endite medial margin was four versus two, and the maxilliped palp article 1 lateral marginal setae were fewer in the West Beach specimens (usually one, occasionally two, versus at least three in Z. turkensis). The West Beach specimens have unequal pairs of lateral setae on pleonites 4 and 5 while $Z$. turkensis has none.

\section{Remarks on variability}

Some of the West Beach H. sasuke specimens that we dissected were larger (females: range 2.54-4.33 mm, males: range 2.05-3.28 mm) than those underlying the descriptions in Tanabe \& Kakui (2019) (females: holotype $2.28 \mathrm{~mm}$, range $1.75-2.88 \mathrm{~mm}$, males: allotype $2.25 \mathrm{~mm}$, range $1.72-2.93 \mathrm{~mm}$ ). We observed a small degree of variability in pleopodal setation among the West Beach specimens. Five or six plumose setae were found on the lateral margins of the basal segments of pleopods 1 and 2, seven in one of these pleopods in the largest female. Three lateral setae were commonly found on the basis of the third pleopods. However, in two smaller males two plumose setae were observed. Four were observed in the largest female. Tanabe \& Kakui (2019) found three lateral setae on the third pleopod basal segment consistently in their dissections. Our small differences in numbers of lateral setae on pleopod bases did not correspond to differences in other morphological characters and suggested a size effect. Consistent with Tanabe \& Kakui (2019), the absence of medial setae on the basal segment of pleopod 3 was stable and independent of size. We found only one plumose seta medial on the endopods of all three pleopods in the West Beach specimens. However, Tanabe et al. (2017) reported intra-species variability in endopod medial setae numbers in $H$. urashima Tanabe, Hayashi, Tomioka \& Kakui, 2017; this weakens the case for the use of this character in species differentiation within Hexapleomera.

Dissected females at West Beach had 8-11 flattened setae in the medial setal row on the pereopod 6 propodus, with higher numbers in larger specimens suggestive of a size effect. Six flattened setae were observed in the smaller holotype from Japan. Tanabe \& Kakui (2019) found stability in the number of setae dorsoproximal on the propodal fixed finger (3-4). This was also the case for the West Beach dissected specimens with the exception of two females that had five setae on one of their chelipeds and four on the other. The number of setae dorsodistal on the cheliped carpus (3-4) also showed excellent stability in H. sasuke (Tanabe \& Kakui 2019). Except for one large female that had five setae on one of its chelipeds and four on the other, this was also the case at West Beach. Our observations do not preclude the use of these characters in differentiating Hexapleomera species but suggest that specimen size needs to be considered in their application, consistent with the recommendation of Wi et al. (2018b) in their study of H. yokjidona Wi, Kang, Lee \& Jeong, 2018 and discussion of Hexapleomera diagnostic characters.

As in Tanabe \& Kakui (2019), variability in the form of the male cheliped was observed at West Beach, with the fixed finger showing a range of profiles from two small triangular processes side by side on the cutting edge in smaller preparatory males to the more mature versions in which the triangular processes had separated completely to become a proximal tooth and a small, dorsodistal triangular process and the dactylus narrowed and more arcuate. The number of setae dorsal on the cheliped fixed finger cutting edge also increased from seven in preparatory males to ten in dimorphic males. We did not determine whether only the most sexually dimorphic males were copulatory. Males with no clear separation of a mid-margin or proximal tooth and the distal process were considered preparatory, recognizing that this may include mature but less dimorphic males.

\section{Further remarks on taxonomy}

Our identification efforts for the West Beach specimens were originally based solely on morphology and suggested 
the genus Hexapleomera, although we had reservations due to antennae that we considered seven-articled and the variability in the form of the male cheliped. The subsequent $\mathrm{CO} 1$ results and available $\mathrm{CO} 1$ sequence data for comparison led us to examine this more closely through a synthesis of published information on species currently assigned to Hexapleomera and Zeuxo.

The most recent diagnosis for the genus Hexapleomera (Tanabe et al. 2017) is provided below.

"Pleon with five pleonites; pleonites 1 and 2 without transverse row of setae. Maxilliped palp article 1 without distal expansion. Antenna with six articles; article 2 without tuft of distal setae. Pleopod 3 slightly reduced. Uropods short, each article two or rarely three times as long as wide; most distal article of uropod not reduced. Sexual dimorphism in cheliped pronounced; chela in sexually dimorphic males about 1.5 times wider than chelipedal carpus."

Tanabe et al. (2017) excluded the character "pereonites 1 to 3 together being wider than long" from the previous diagnosis of Bamber (2012a), with justification based on non-conformity with this character by H. bultidactyla Esquete \& Fernandez-Gonzalez, 2016 and H. wombat Bamber, 2012. We found considerable variability in the degree of compactness of pereonites 1 to 3 among both the female and male $H$. sasuke specimens at West Beach and no association of this compactness with other morphological characters. Specimens also showed variability in the degree of body curvature requiring the use of a lateral view for accurate length measurements in some cases. In contrast to the Bamber (2012a) and Edgar (2008) diagnoses, Tanabe et al. (2017) also included a maxilliped palp article 1 without distal expansion, antenna article 2 without a tuft of distal setae, uropods short with segments twice or rarely three times as long as wide and a metric to guide assessment of the degree of sexual dimorphism. Bamber (2012a) did not include characters relating to the antennule (four articles, first article over 2.5 times length of second article, terminal article with five to eight aesthetascs) and that antenna article 2 is much longer than wide from the diagnosis given in Edgar (2008). Sieg (1980)'s diagnosis for Hexapleomera also included a partly fused labial palp and crotchets distal on pereopod carpi that were not clearly enlarged.

The most recent diagnosis for the genus Zeuxo (Larsen 2014), with the suggested modification relating to pleopod setation from Tzeng \& Hsueh (2015) included, is provided below.

"Five pleonites present plus pleotelson. Antennule with four articles, first article over 2.5 times as long as second article, terminal article with two to eight aesthetascs. Antenna with seven articles, article 2 longer than wide. Labium outer lobe with small terminal process (palp rudiment). Maxilliped basis with one or two distal setae; palp article 1 with one or two outer setae; article 2 with one outer seta. Pereopod 1 coxa with anterior bulge. Pleopods basis without setae or with one, occasionally two to five plumose setae on inner margin and three to eight setae on outer margin, endopod inner margin with one to six plumose setae. Uropod with three to seven articles, terminal article not reduced."

Compared with the earlier diagnosis from Edgar (2008), Larsen (2014) did not include the requirement that the maxillule endite have eight terminal spiniform setae and added the characters relating to the maxilliped. Nine large terminal spiniform setae have been observed on the maxillule endite of $Z$. novaezealandiae (Thomson, 1879) (Bird 2008), Z. turkensis (Larsen 2014), and Z. kermadecensis Bird, 2015 (Bird 2015), one seta noted as thinner than the others in the last case. Wi et al. (2018c) observed eight "pinnate spiniform setae" and one "slender setulose seta" terminal on the maxillule endite of $Z$. gracilis Wi, Jeong \& Jeong, 2016. Only seven spiniform setae were observed in Z. bimbache García-Herrero, Sánchez, García-Gómez, Pardos \& Martínez, 2017 (García-Herrero et al. 2017), Z. koreaensis Larsen, 2014 (Larsen 2014), and the recently described Z. ezoensis Okamoto, Oya \& Kakui, 2020 (Okamoto et al., 2020) lending further support to this revision. Zeuxo turkensis has at least three lateral marginal setae on the maxilliped palp first article, which would, if the diagnosis were applied absolutely, exclude it from the Zeuxo genus. Assessments reported by Bird (2008) showed that the first antennule article ranges from 1.46 to 3.67 times the length of the second article in published figures of female Zeuxo species, suggesting that a 2.5 cut-off for this ratio is not robust for Zeuxo diagnosis. Sieg (1980)'s earlier work also used an articulated labial palp to differentiate the genus Zeuxo in his taxonomic keys.

At time of manuscript preparation, there were 37 Zeuxo species and ten Hexapleomera species in the WoRMS database (WoRMS 2021), excluding those that were designated nomen nudum. Zeuxo ezoensis has been added and 
Z. maledivensis Sieg, 1980 reinstated, both as per Okamoto et al. (2020), a recent article kindly pointed out by a reviewer. Our assessment now encompasses 34 Zeuxo species where sufficient morphological detail was available in accessible literature. It includes the recent redescription of Z. seurati (Nobili, 1906) by Bird (2019) and Z. insularis (Miller, 1940) (also in Sieg 1980), but excludes Z. beringi Kudinova-Pasternak, 1989, Z. kurilensis (Kussakin \& Tsareva, 1974), Z. marmoratus (Nordenstam, 1930), Z. tenuicornis (Haswell, 1882) and Z. westwoodiana Templeton, 1840 .

Table 3 contains a summary of species level information for morphological characters in the most recent genus diagnoses for the ten Hexapleomera and 34 Zeuxo species. Additional characters discussed in the text have also been included. A pleon with five pleonites and a lack of transverse rows of plumose setae on pleonites 1 and 2 have not been included as they are met without question in both genera.

Based on the morphological descriptions in the literature, the choice of Zeuxo or Hexapleomera depends on [1] whether they have six or seven articles in the antenna, [2] the degree of expression of the pereopod 1 coxa anterior process, [3] the degree of reduction of pleopod 3, [4] the degree of fusion of the labial palp to the outer lobe, and [5] the degree of sexual dimorphism observable in chelipeds and antennae. We discuss these characters in order below. None are without challenges.

In the presence of numerous distal setae, a tiny terminal antennal article can be hard to detect using standard optical techniques. After careful assessment, we still consider a very tiny terminal cap, a minute seventh article, to be present on the antennae in the West Beach specimens. Scanning electron microscopy was not available for this project to resolve ambiguity. Our assessment conflicts with Tanabe \& Kakui (2019). As pointed out by Larsen (2014), the assessment of a slight versus absent anterior process on the pereopod 1 coxa can be subjective. We assessed the anterior process on the West Beach specimens as slight, in contrast with Tanabe \& Kakui (2019) who consider it absent. We are not stating that Tanabe \& Kakui (2019) are incorrect in either of these cases. We are merely reporting the results of our independent assessment illustrating the lack of robustness of these characters in the genus diagnosis. The reduction in pleopod 3 in the West Beach specimens is slight, but similar in degree to previously described Hexapleomera species. However, Z. turkensis also has a reduced pleopod 3 in the male, even more so in the female. Three other species assigned to Zeuxo also have some reduction in the third pleopod-Z. fresii Sieg, 1980 (Sieg, 1980), Z. andaminimus Bamber \& Chatterjee, 2010 (Bamber \& Chatterjee 2010), and the recently described Z. ezoensis (Okamoto et al. 2020). Z. ezoensis has pleopods with setation very similar to H. sasuke. Fusion of the labial palp with the outer lobe was initially assessed as ambiguous or partial in some dissections of the West Beach specimens due to the direction of view and the lobe being partially obscured. The clearest views however, showed that the palps are fused to the labium outer lobes.

Hexapleomera sasuke shows clear sexual dimorphism in the chelipeds, antennules, and antennae. Sieg (1980)'s diagnosis for Zeuxo does, however, specify some sexual dimorphism namely an enlarged cheliped, an anteriorly narrowing cephalothorax, and usually more elongate antennules and antennae in the male. Tanabe et al. (2017) suggest using the ratio of the widths of the cheliped propodus (chela) and carpus in dimorphic males as a measure of sexual dimorphism, with a value of 1.5 for the ratio for inclusion in the Hexapleomera genus. We would like to suggest the ratio of lengths of the cheliped carpus and propodus $(C(L): P(L))$ as a metric for sexual dimorphism to differentiate between Hexapleomera and Zeuxo, with the locations we used for these measurements shown in Figure 8. Values extracted from figures in the literature are provided in Table 3. Hexapleomera males, preparatory and dimorphic, have a $\mathrm{C}(\mathrm{L}): \mathrm{P}(\mathrm{L})$ of $0.4-0.6$, lower in more strongly sexually dimorphic specimens. Males of Zeuxo species generally have ratios $>0.6$. However, characters based on the male cheliped suffer from the disadvantages that the male cheliped form in Hexapleomera shows variability with development stage and also among mature specimens (Wi et al. 2018a; Tanabe \& Kakui 2019) and strongly dimorphic males may not always be found in a sample. Bamber (2012b) reported proximal and distal "tooth-like" apophyses dorsal on the cheliped fixed finger of a single male specimen designated Zeuxo sp. B, 2mm in length, and collected from Cape Verde. As figured, its C(L):P(L) is between 0.5 and 0.6. The male was found in samples with females that were given the new species designation $Z$. coturnix Bamber, 2012. From the partial description, it had three aesthetascs, eight setae terminal on its antennule, four uropod segments, but the number of articles in its antenna was not reported.

With support from phylogenetic analyses based on COI sequences, Tanabe \& Kakui (2019) suggest that two groups may exist within the Hexapleomera genus, a "wombat" group and a "robusta" group, distinguished morphologically on the basis of the number of segments in the uropod and the presence of a process proximoventral on the propodus of the dimorphic male cheliped. Our examination of the information in the literature (Table 3) suggests 
that the dorsodistal ornamentation of the pereopod 6 propodus also coincides with this grouping, the "robusta" group having a cluster of setae, two to four serrate or simple setae between two longer simple setae, and the "wombat" group having only the two longer simple setae. (A subdistal dorsal PSS is reported on the pereopod 6 propodus of all species except $H$. satella Bamber, 2012 and H. wombat). The "wombat" group also tends to have fewer plumose setae lateral on the first three pleonites and is also consistent in having only one seta distal on the maxilliped basis. Tanabe and others (Tanabe et al. 2017; Tanabe \& Kakui 2019) observed some interspecies variability in the latter of these characters in $H$. sasuke and $H$. urashima, however.

Considering other characters that we examined, all of the Hexapleomera species described to date have similar lacinia mobilis morphologies, the left one wide and distally crenulated and the right narrow, subrectangular, peglike, but conspicuous. However, fourteen species of Zeuxo have apparently similar lacinia mobilis morphologies, three of these (Z. coralensis Sieg, 1980, Z. mooneyi Edgar, 2008, and Z. normani (Richardson, 1905)) having slightly more reduced right laciniae mobiles but still considered peg-like. All seven non-stygophilic Zeuxo species with shorter, four-segmented uropods fall within the fourteen (Table 3). The Hexapleomera species show consistency in the shape of the dorsal margin and cutting edge of the cheliped fixed finger in females and, in males, the presence of a ventral process on the cheliped carpus and a subdistal indent on the cheliped merus. Another character that deserves mention is the articulation of the maxillule palp. Sieg (1980) explicitly included a one-articulate maxillule palp in the Tanaidae (=Tanaididae) family definition but commented that there is always a location where a discontinuity is evident, indicating that it is the product of intergrowth. The palp in Z. turkensis appears bi-articulate (Larsen 2014) and is also assessed as bi-articulate in H. sasuke (Tanabe \& Kakui 2019). We assessed the palp as uniarticulate in the West Beach specimens, but a discontinuity was evident in most dissected specimens, arguably interpretable as a joint in some.

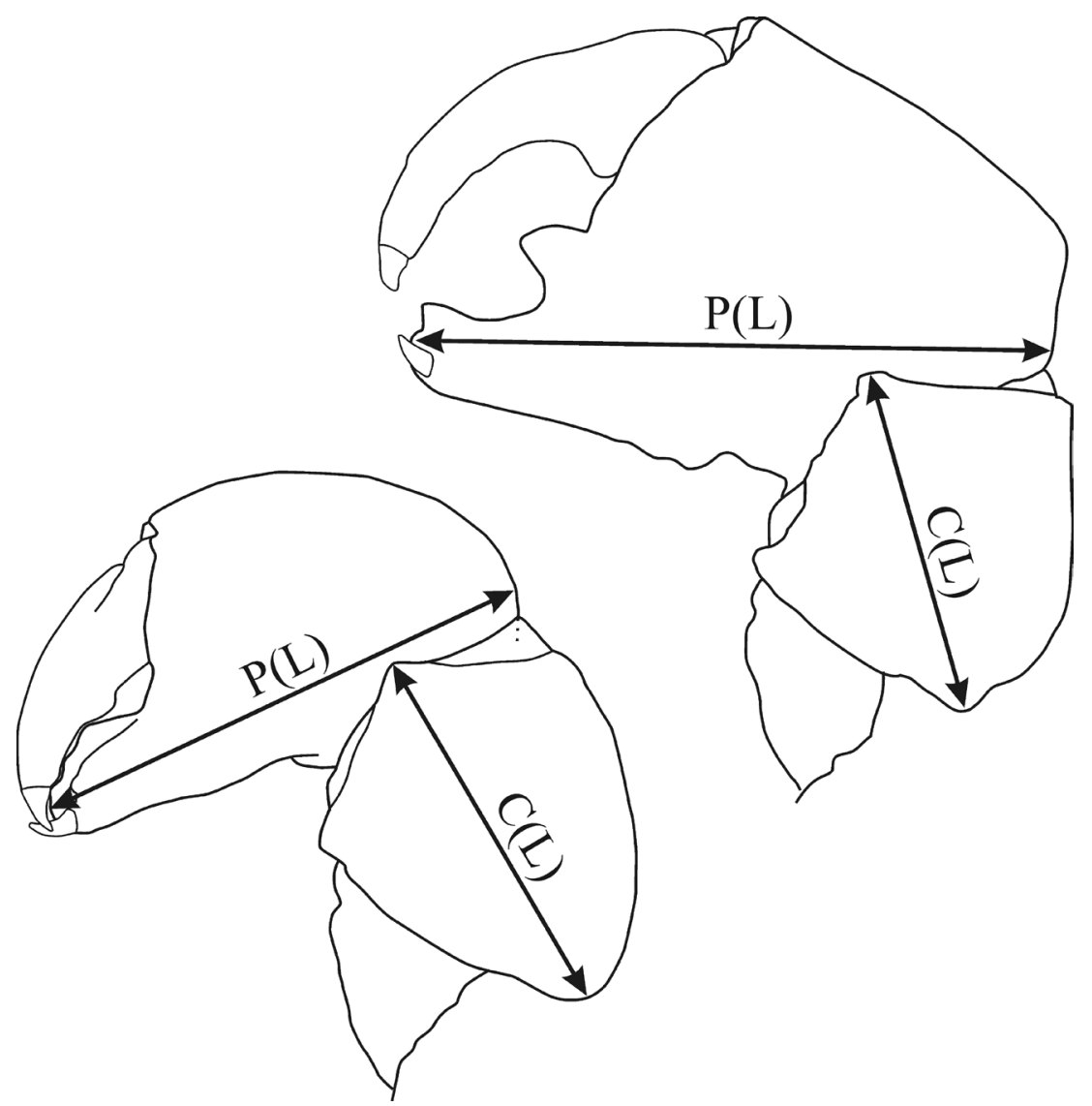

FIGURE 8. Diagrams showing location of measurements of cheliped carpus and propodus lengths.

Overall, Hexapleomera species show consistency with respect to slight reduction in size and setation of pleopod 3, the form of the left and right laciniae mobiles, the shape of the dorsal margin and cutting edge of the female cheliped fixed finger, the presence of a ventral process on the cheliped carpus and a subdistal indent on the cheliped merus in males, notable sexual dimorphism in the cheliped form, and coxa 1 with only a slight or no anterior 
apophysis. This combination of characters would be useful to distinguish Hexapleomera from Zeuxo but will still present challenges when strongly sexually dimorphic males are not present in a sample.

Considering higher taxonomic levels, as more species have been discovered, described, and assigned to the different genera in the subfamily Pancolinae Sieg, 1980, the boundary between the tribes Anatanaini Sieg, 1980 and the Pancolini Sieg, 1980 has become less well-defined. An argument can be made that Hexapleomera resides in either tribe. Whether the notable sexual dimorphism is considered weak (Anatanaini) or strong (Pancolini) depends on the reference frame. The species has five pleonites, a dubious anterior apophysis on coxa 1, a consistent but only slight reduction in pleopod 3, several plumose setae on the lateral margins of the first three pleonites, and a clear, ovoid labial palp, comparable in size to those illustrated for some Zeuxo species but fused or partly fused to the outer lobe. A comparison of Sieg (1980)'s drawings of specimens from the different tribes shows that the Hexapleomera genus is also ambiguous with respect to meeting the Pancolini character "enlargement of the spines on the carpus of the anterior pereopods". Currently, the only factors keeping Hexapleomera in the Pancolini are the notable degree of sexual dimorphism in the chelipeds and antennae and the reduction of the third pleopod (Bird 2008, Bamber 2005) and neither of these is definitive. Within the Pancolini, Aviatanais Bamber, 2005, Monoditanais Sieg, 1980, and Pancolus Richardson, 1905 remain monotypic with morphological characters that clearly distinguish them from other tribe members. Pancoloides Sieg, 1980 also remains monotypic but aligns with the tribe less strongly, but more so than Hexapleomera which now has 10 species. Within the Anatanaini, Anatanais Nordenstam, 1930 has only two species, Zeuxoides Sieg, 198012 species, and Zeuxo a multitude of 37 species.

Until more molecular data are available to inform taxonomic revisions, including those at higher levels, and to support morphological definitions of genera in the Tanaididae, it may be beneficial to retain a more comprehensive morphological diagnosis for the genus Hexapleomera that considers its location within the broader subfamily of Pancolinae. We suggest the following for Hexapleomera-

In mature specimens: Pleon with five pleonites; pleonites 1 and 2 without transverse row of (plumose) setae, but with lateral plumose setae. With three pairs of pleopods. Pleopods 1 and 2 basal articles with one plumose seta on medial margins and four to seven plumose setae on lateral margins; endopod medial margins with one, occasionally two, plumose setae. Pleopod 3 slightly reduced. Uropod short, each segment two, or rarely three, times as long as wide; most distal segment of uropod not reduced, never cap-like. Antennule with four articles, first article more than twice as long as second article (2.2-ca. 3.0x in females, to $>3.5 \mathrm{x}$ in males), with three to eight terminal aesthetascs. Antenna with six articles, article 2 longer than wide ( $>1.2 \mathrm{x}$ in females, $>2.0 \mathrm{x}$ in males), without tuft of distal setae. Labium outer lobe with partly or completely fused small terminal process (palp rudiment). Maxillule endite with eight, rarely nine, terminal spiniform setae. Maxilliped basis with one or two distal setae. Maxilliped palp article 1 lateral margin with one or two setae, without lateral distal expansion; article 2 lateral margin with one seta. Lacinia mobilis on right mandible present but reduced, narrow and peg-like. Lacinia mobilis on left mandible wide, subrectangular with digitate or undulate distal margin. Coxa 1 with slight or no anterior apophysis. Length of pereopod 2 and 3 carpal crotchets one third or less of the length of the propodus. Cheliped carpus with ventral process in males, less pronounced or absent in females. Cheliped merus with subdistal ventral indent in males. Cutting edge of cheliped fixed finger in females with proximal invagination and distal expansion into lamella with undulating margin and rounded end. Sexual dimorphism in chelipeds pronounced; cheliped carpus length $0.4-0.6 \mathrm{x}$ length of propodus in mature males, lower value in more strongly sexually dimorphic specimens. Sexually dimorphic males with or without proximal apophysis on dorsal margin of cheliped fixed finger.

Applying the same set of characters to Zeuxo gives the following-

In mature specimens: Pleon with five pleonites; pleonites 1 and 2 without transverse row of (plumose) setae, and with or without lateral plumose setae. With three pairs of pleopods; pleopod basal articles without setae or with one, occasionally two to five, plumose setae on medial margin and three to eight, rarely more, plumose setae on lateral margin, endopod medial margin with one to six plumose setae. Pleopod 3 usually as pleopods 1 and 2, occasionally slightly reduced. Uropod short to long (three to seven segments), terminal segment not reduced, never cap-like. Antennule with four articles, first article two to three times as long as second article, terminal article with one to eleven aesthetascs (1-5 in females, rarely more; 3-11 in males). Antenna with seven articles; article 2 longer than wide (slightly to clearly, $>1.2 \mathrm{x}$ ), without tuft of distal setae. Labium outer lobe with articulated small terminal process (palp rudiment). Maxillule endite usually with eight terminal spiniform setae, occasionally seven or nine. Maxilliped basis usually with zero to two distal setae, rarely three or four. Maxilliped palp article 1 lateral margin usually with zero or one setae, sometimes two or three, usually without or rarely with slight distal expansion; article 
2 lateral margin with one seta, rarely none. Lacinia mobilis on right mandible variable, from reduced narrow and peg-like to absent. Lacinia mobilis on left mandible variable, from wide, well-developed, digitate distally to reduced peg-like or sub-conical. Coxa 1 with slight to significant anterior apophysis. Length of pereopod 2 and 3 carpal crotchets variable, occasionally greater than one third of the propodus length, rarely reaching half of propodus length. Cheliped carpus without ventral process in males, also absent in females. Cheliped merus without subdistal ventral indent in males. Cutting edge of cheliped fixed finger in females of variable form. Sexual dimorphism in chelipeds not pronounced; cheliped carpus length $>0.6$ times length of propodus in males. Sexually dimorphic males without proximal apophysis on dorsal margin of cheliped fixed finger.

Based on figures in the literature, this parameterisation of sexual dimorphism also aids to differentiate Hexapleomera from the relatively species rich Anatanaini genus Zeuxoides $(\mathrm{C}(\mathrm{L}): \mathrm{P}(\mathrm{L})=0.6-0.8$ from the data available for eight of the 12 species; females 0.7-1.0). Anatanais Nordenstam, 1930 and Aviatanais Bamber, 2005 only have information on females available in the literature.

We have not examined actual specimens of $Z$. turkensis, a limitation of our study, but consider some of the morphological differences described earlier as inconsistent with $H$. sasuke. We think it premature to synonymise $H$. sasuke with $Z$. turkensis without a more extensive examination of actual specimens of $Z$. turkensis collected from the geographic location of their original collection. A broader look using both morphological and molecular techniques would be required to better judge intra-species variability and support any synonymising.

The West Beach Hexapleomera specimens represent an additional record of $H$. sasuke found at a location geographically distant from the type locality. In a companion survey, H. sasuke, identified using morphology only, was observed at three floating dock locations in Spencer Gulf: the Port Lincoln Marina (March, 2010), the Port Augusta Boat Ramp (March, 2010), and Whyalla Marina (March and September, 2010).

\section{Concluding comments}

The primary goal of this project was the identification of the two dominant species of Tanaidacea observed in timeseries samples collected at West Beach, Adelaide, between October 2009 and September 2010. With additional sampling in January 2015 to obtain specimens with sufficiently intact DNA, these species have been identified as Hexapleomera sasuke and Tanais adelaidensis, the latter designated a new species.

The current classification of the tribes, and, perhaps in some cases also genus, within the family Tanaididae is not robust (Bird 2008). The Hexapleomera genus currently occupies a somewhat grey morphological position between the Anatanaini and Pancolini tribes and overlaps significantly with the diagnosis for the Zeuxo genus. Sieg's careful work (Sieg, 1980) in the Tanais genus was complicated by the lack of type material for the reportedly widespread and highly synonymised type species. As discussed by Larsen et al. (2014), morphological characters can vary within a species of tanaid with sex and developmental stage and the picture is further complicated by the possibility of cryptic species complexes. A clear limitation of the morphological discussion presented in our study is the reliance on character information extracted from the literature rather than examination of types and actual specimens of other identified species.

There is only a limited body of molecular data currently available for these taxa. A recent assessment of $\mathrm{CO1}$ sequences from different genera within the broad Tanaididae group was conducted by Tanabe et al. (2017); it was determined that the region of mitochondrial DNA amplified by the Folmer et al. (1994) primers is not useful for reconstructing phylogenetic relationships in the Tanaididae group. That said, the $\mathrm{CO} 1$ sequence data can still aid in the investigation of intra-species morphological variability and life cycles, and may have utility assessing relationships at the genus level. In our study, the CO1 data were derived only from the smaller single sampling in January 2015. Dissections of January 2015 specimens were compared in detail with times-series specimens collected in the same season and no consistent differences were noted, giving confidence that they were the same species. However, given the similarity between species of Hexapleomera when examined in their non-dissected state, it is possible that other species in this genus are present in other samples within the time-series.

An additional goal of this work was to assess whether the tanaid species were introduced or native. Species in both Hexapleomera and Tanais have been accused of cosmopolitan distributions in the past. Tanaidacea do not have a pelagic dispersal life stage so options for long distance transport are limited (Larsen 2005). Rafting on natural or anthropogenic material and human transport via ballast water and hull biofouling have received considerable atten- 


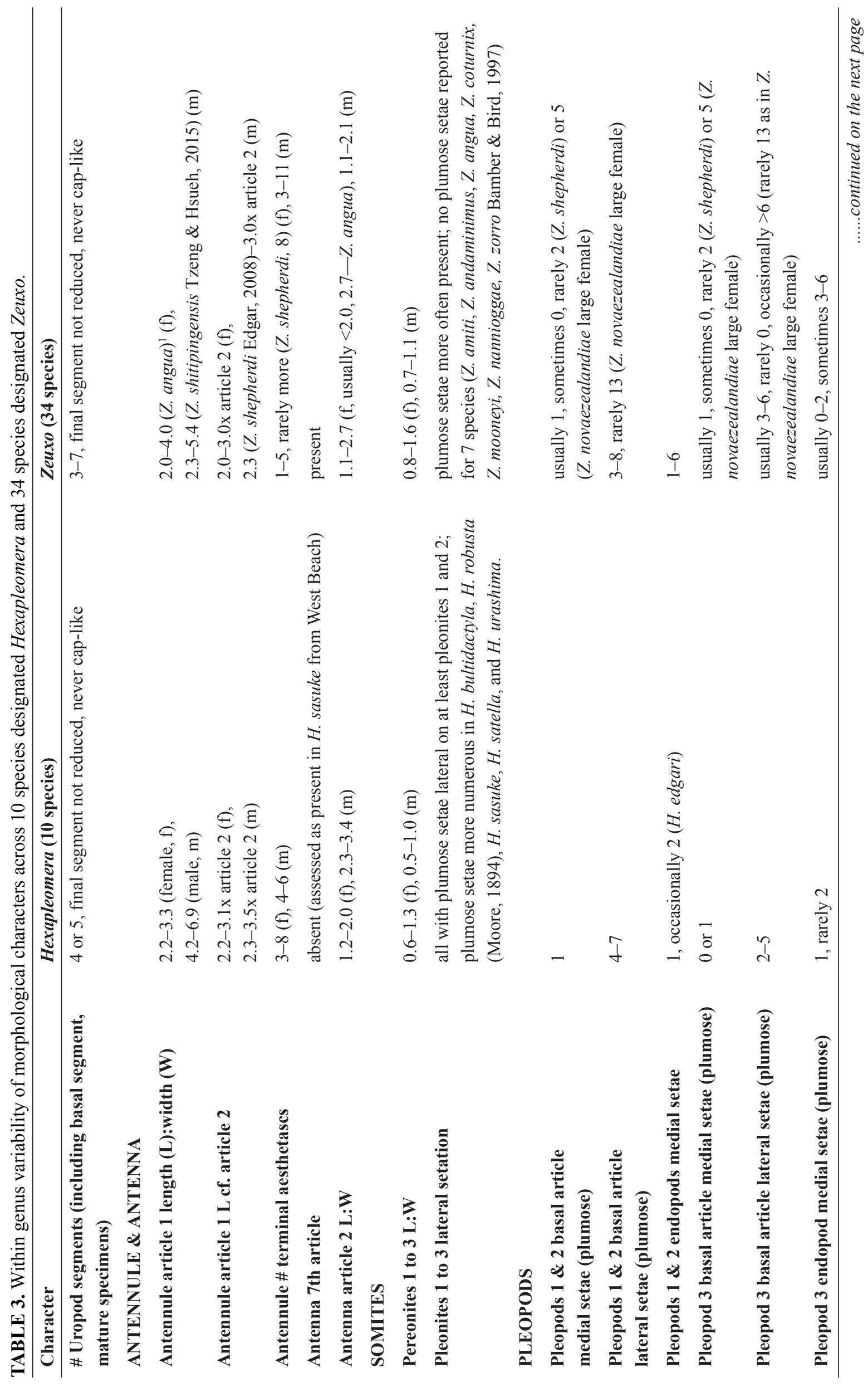

114 - Zootaxa 4996 (1) (c) 2021 Magnolia Press 


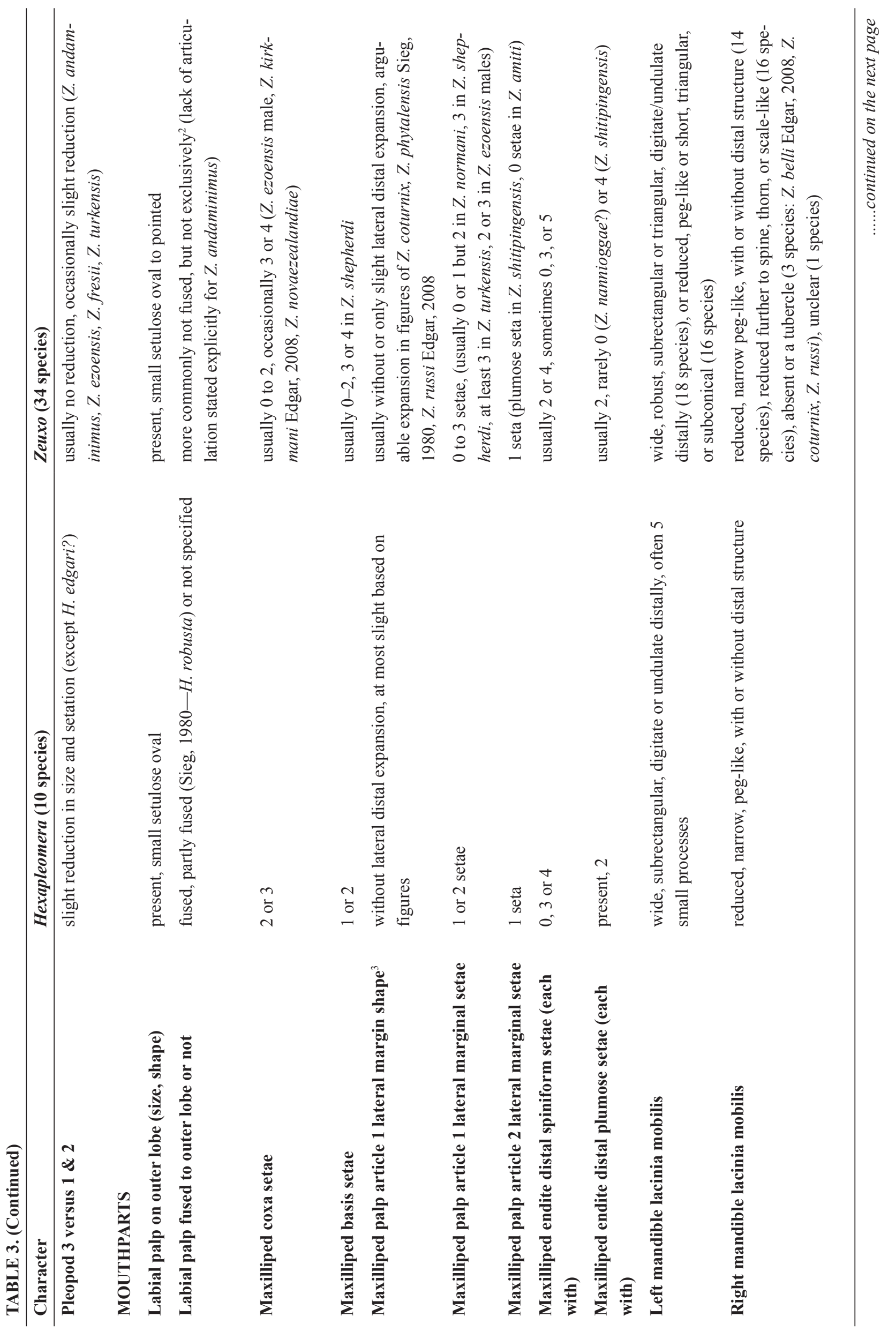

WEST BEACH TANAIDIDAE 


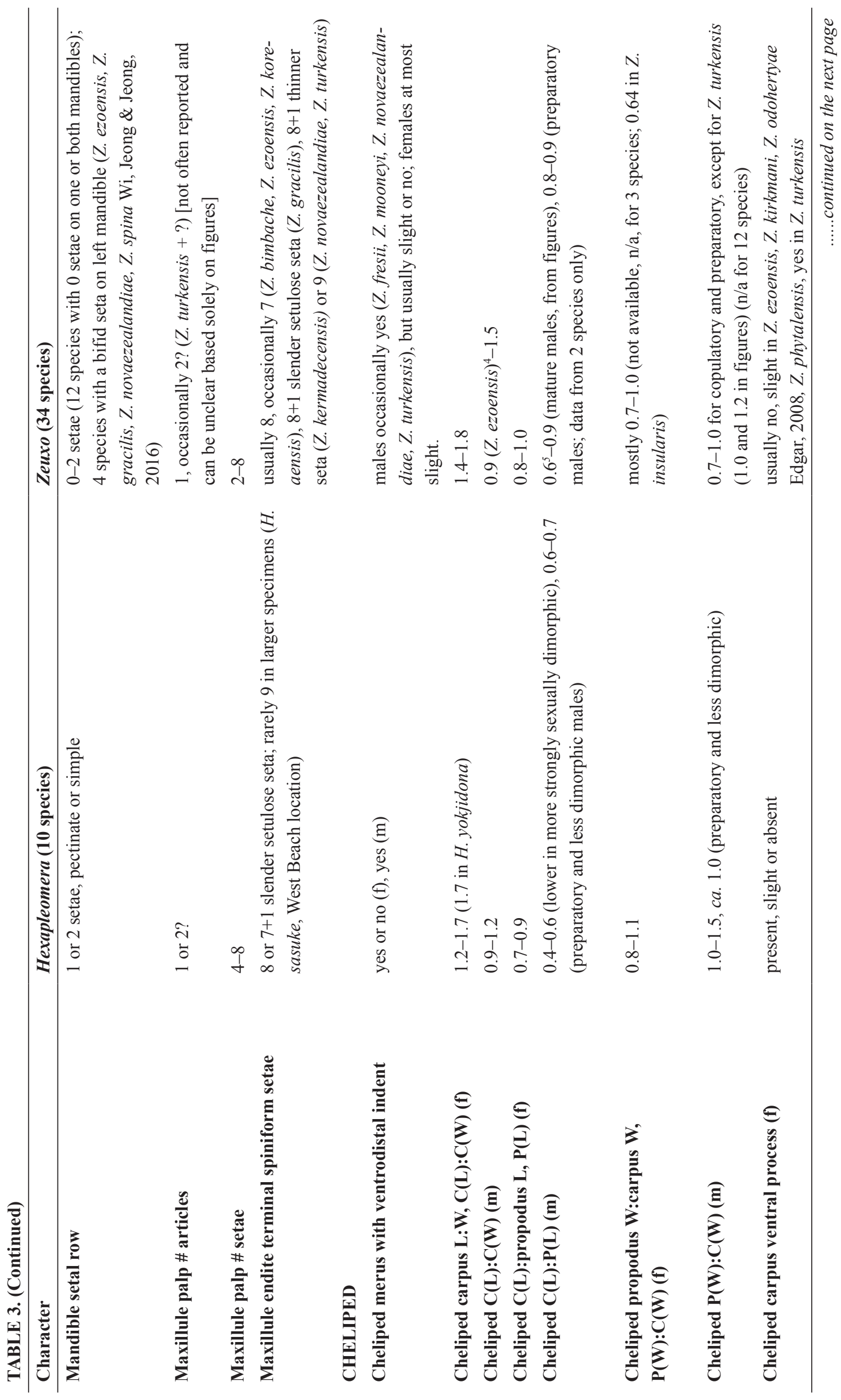




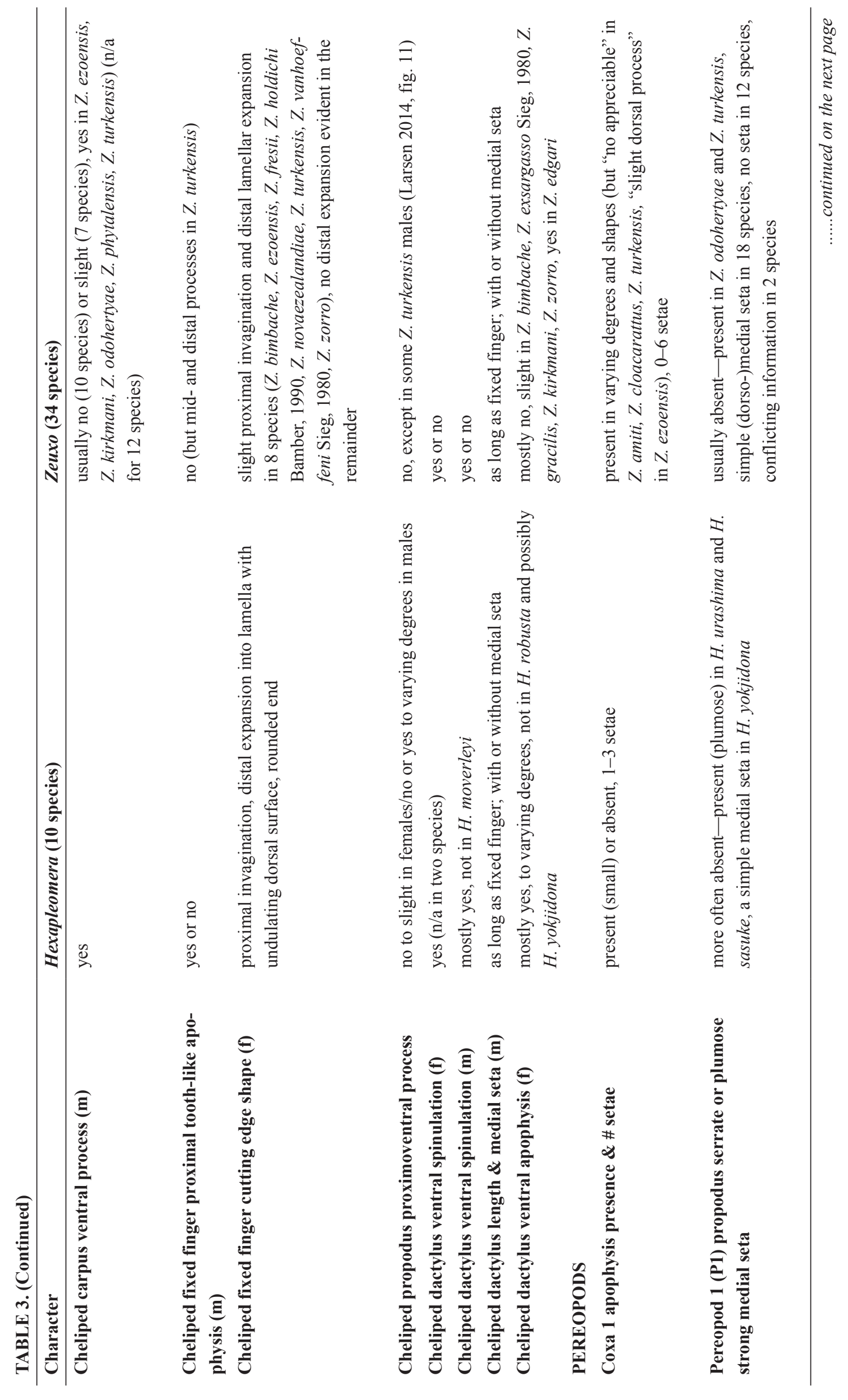

WEST BEACH TANAIDIDAE 


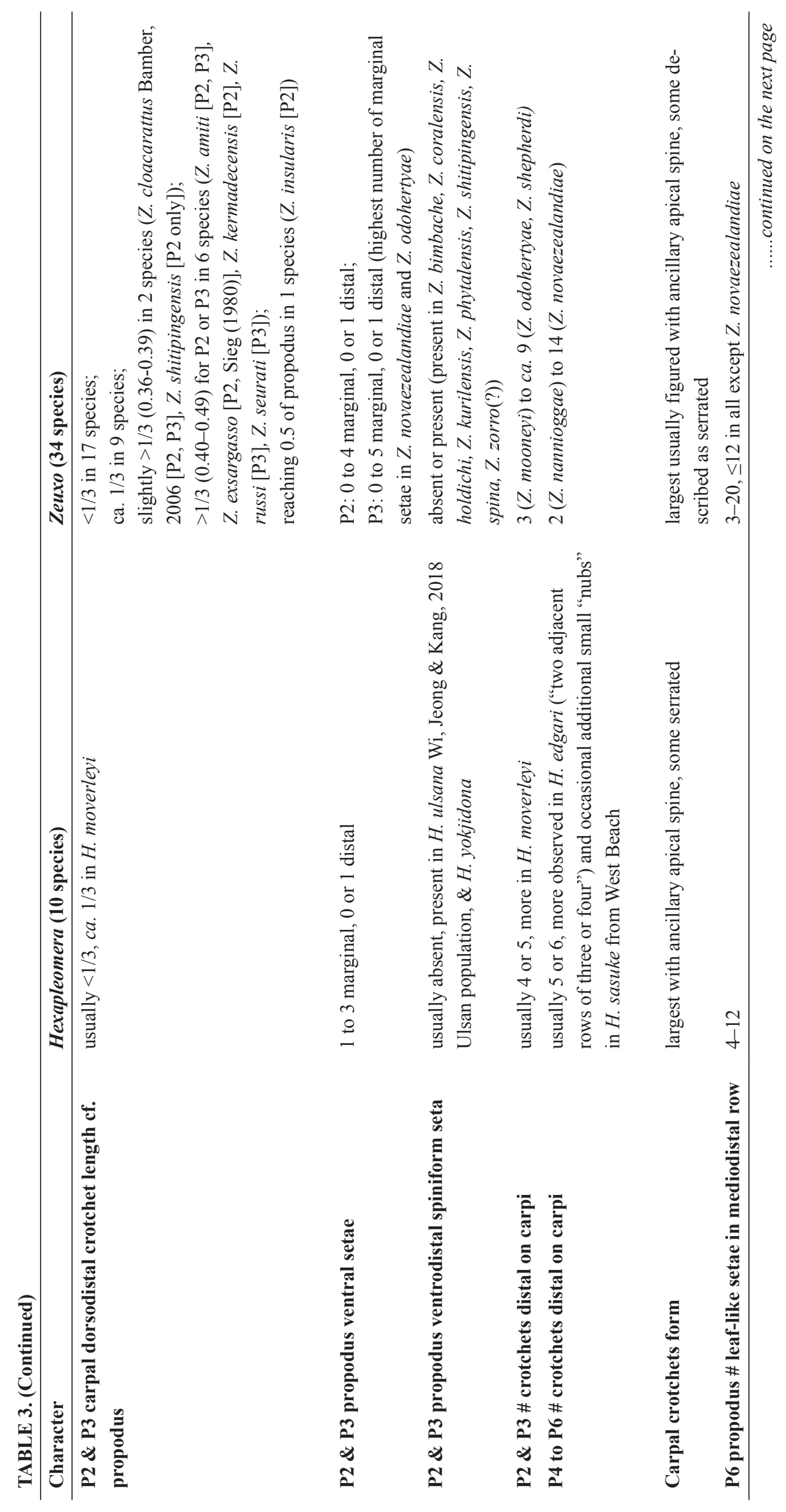



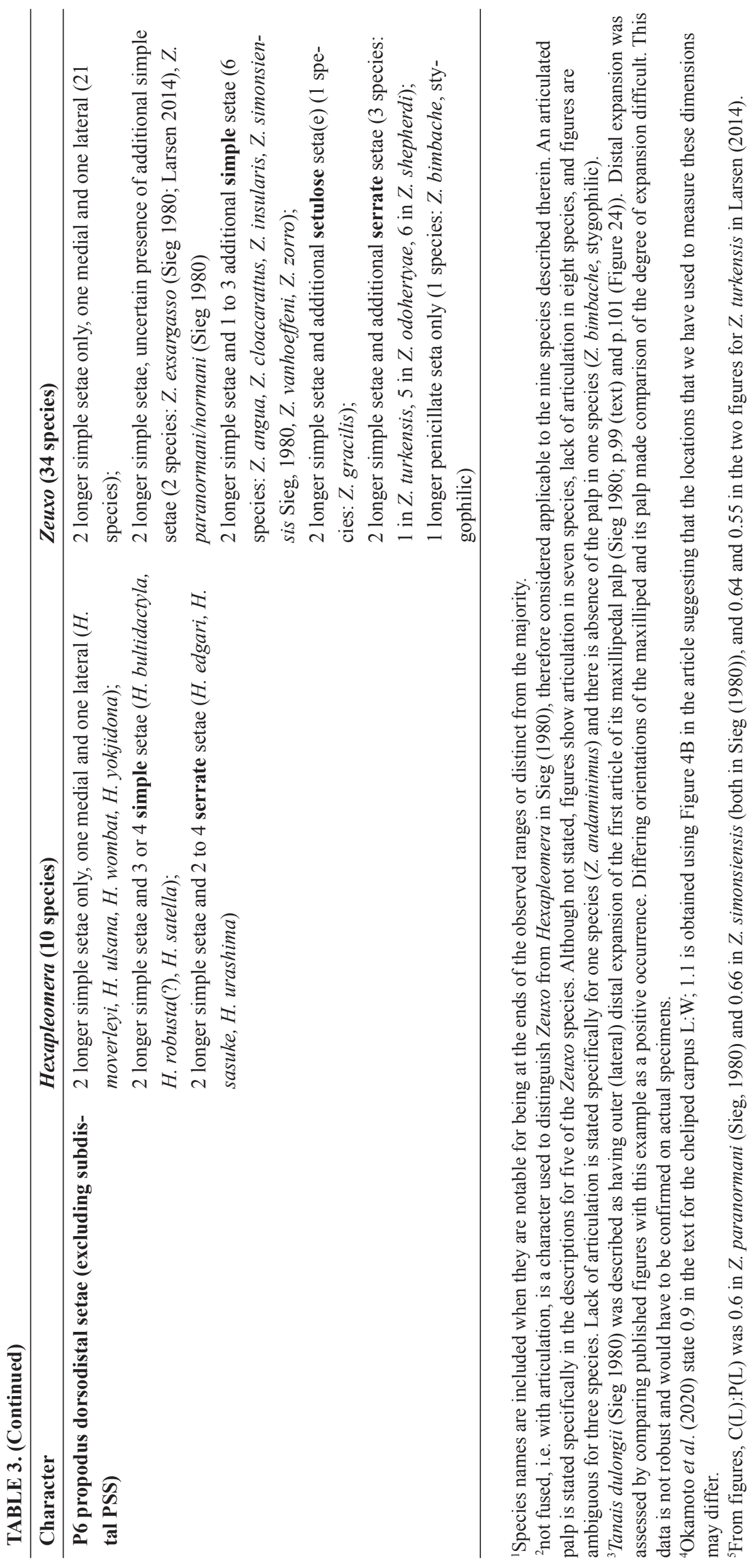

WEST BEACH TANAIDIDAE 
tion in introduced and invasive species research (Carlton \& Hodder 1995; Carlton 1996; Coutts et al. 2003; Ashton et al. 2006; Wells et al. 2009; Chapman et al. 2013; Chan et al. 2015; Darling \& Carlton 2018). Van Haaren \& Soors (2009) reported Sinelobus stanfordi (Richardson, 1901), a member of the Tanaididae, subfamily Sinelobinae Sieg, 1980, as a recent invader of Dutch and Belgian estuarine waters based on observations at well-monitored sites. Despite the lack of pelagic life stage, an anthropogenic component to dispersal is possible for these tube-dwelling peracarids. Artificial floating docks represent a habitat favourable for species transported in hull fouling communities (Leclerc et al. 2020). The agreement between the $655 \mathrm{nt}$ CO1 sequences from the West Beach Hexapleomera species and H. sasuke collected in Japan, and perhaps also with the shorter COI sequence from a Zeuxo species collected in the Eastern Mediterranean, provide evidence supporting the long distance transport of this tanaid species. The ability to produce more than one brood per season would contribute to successful colonisation (Geburzi $\&$ McCarthy 2018). Hexapleomera sasuke is clearly associated with fouling communities and now has evidence for occurrence at geographically distant locations. Its region of origin remains unclear, however, so it remains cryptogenic. The same can be said of Tanais adelaidensis.

With the increasingly complex picture of intra-species morphological variability (Kakui et al. 2017; Wi et al. 2018a; Tanabe \& Kakui 2019) but high inter-species similarity, and sometimes reliance on characters that have some subjectivity in their assessment, the Tanaididae group would benefit from a collaborative effort to develop a molecular framework within which to interpret detailed morphological data. Publication of comprehensive and robust detailed morphological descriptions along with molecular data, such as those provided recently (Tanabe et al. 2017; Wi et al. 2018a; Tanabe \& Kakui 2019; Okamoto et al. 2020) is key for the necessary taxonomic revisions of the Tanaididae group. Building further on the earlier work by Larsen and others (Larsen 2001; Drumm 2010; Kakui et al. 2011; Larsen 2014; Larsen et al. 2014), identification of additional informative genetic sequences and a larger CO1 dataset are required. In combination, detailed morphological and molecular data offer a powerful and exciting means to better define and investigate intra-species variability, increase confidence in species identifications, and thus increase understanding of the biogeography and phylogeny of this challenging group of peracarids. In addition, it is evident that some tanaid species, notably those associated with fouling communities, have the potential to be found in geographically distant locations despite the absence of a pelagic larval stage.

\section{Acknowledgements}

Dr. Valerie K. Tait, an independent researcher, was affiliated with the Canadian Museum of Nature (CMN) as Research Associate from 2013-2019 while most of this work was conducted. We gratefully acknowledge the CMN for the use of their facilities to conduct the identification work, for funds to Dr. Kathleen E. Conlan for early sorting and counting of samples, and for the illustrations. Thanks are due to Dr. R. N. Baldock, State Herbarium, Adelaide, for the macroalgae identifications. Dr. Conlan was supported by a visiting scholar fellowship from Flinders University while conducting the time-series sampling. Several other individuals deserve mention for their help in the collection of samples: Ed Hendrycks, Ryan Baring, Tanith Ramsdale, and Shea Cameron. Thanks to Dr. Kim Larsen for his advice on DNA work in tanaids before we embarked on that component of the project. Many thanks to Roger Bull for his guidance and skill in the Molecular Biodiversity Laboratory at the CMN. Special thanks to Susan Laurie-Bourque for her skills, patience, and attention to detail in her illustrations of the tanaids and figure preparation. Thanks to Orlando Lam-Gordillo for providing the map for Figure 1. Our appreciation also to the anonymous reviewers who provided detailed comment on the manuscript and to Dr. Graham Bird for his feedback, both of which led to a much-improved paper.

\section{References}

Ahyong, S.T. \& Wilkens, S.L. (2011) Aliens in the Antipodes: Non-indigenous Marine Crustaceans of New Zealand and Australia. In: Galil, B.S., Clark, P.F. \& Carlton, J.T. (Eds.), In the Wrong Place-Alien Marine Crustaceans: Distribution, Biology and Impacts. Springer Netherlands, Dordrecht, pp. 451-485. https://doi.org/10.1007/978-94-007-0591-3_16

Albano, M.J. \& Obenat, S.M. (2019) Fouling assemblages of native, non-indigenous and cryptogenic species on artificial structures, depths and temporal variation. Journal of Sea Research, 144, 1-15. 
https://doi.org/10.1016/j.seares.2018.10.002

Ashton, G., Boos, K., Shucksmith, R. \& Cook, E. (2006) Risk assessment of hull fouling as a vector for marine non-natives in Scotland. Aquatic Invasions, 1 (4), 214-218. https://doi.org/10.3391/ai.2006.1.4.4

Audouin, V. (1826) Explication sommaire des planches de Crustacés de l'Égypte et de la Syrie, publiées par Jules-César Savigny, membre de l'Institut; offrant un exposé des caractères naturels des genres, avec la distinction des espèces. In: Savigny, J.C., Description de l'Égypte, ou recueil des observations et des recherches qui ont été faites en Égypte pendant l'expédition de l'armée française, publiée par les ordres de Sa Majesté l'Empereur Napoléon le Grand. Histoire naturelle. Imprimerie impériale, Paris. Animaux invertébrés, 1 (4), 92.

Bamber, R.N. (1990) A new species of Zeuxo (Crustacea: Tanaidacea) from the French Atlantic coast. Journal of Natural History, 24, 1587-1596. https://doi.org/10.1080/00222939000770911

Bamber, R.N. (2005) The Tanaidaceans (Arthropoda: Crustacea: Peracarida; Tanaidacea) of Esperance, Western Australia, Australia. In: Wells, F.E., Walker, D.I. \& Kendrick, G.A. (Eds.), The Marine Flora and Fauna of Esperance, Western Australia. Western Australia Museum, Perth, pp. 613-728.

Bamber, R.N. (2006) Shallow water tanaidaceans (Crustacea: Peracarida: Tanaidacea) from New Caledonia and the Loyalty Islands. Zootaxa, 1108 (1), 1-21. https://doi.org/10.11646/zootaxa.1108.1.1

Bamber, R.N. (2008) Tanaidaceans (Crustacea: Peracarida: Tanaidacea) from Moreton Bay, Queensland. Memoirs of the Queensland Museum - Nature, 54 (1), 142-218. Available from:

https://www.qm.qld.gov.au/About+Us/Publications/Memoirs+of+the+Queensland+Museum/MQM+Vol+54\#.XfVlmuhKi70 (accessed 22 November 2011)

Bamber, R.N. (2012a) A re-assessment of Hexapleomera Dudich, 1931 (Crustacea: Tanaidacea: Tanaidae), with designation of three new species. Zootaxa, 3583 (1), 51-70. https://doi.org/10.11646/zootaxa.3583.1.4

Bamber, R.N. (2012b) Littoral Tanaidacea (Crustacea: Peracarida) from Macaronesia: Allopatry and provenance in recent habitats. Journal of the Marine Biological Association of the United Kingdom, 92 (5), 1095-1116. https://doi.org/10.1017/S0025315412000252

Bamber, R.N. \& Bird, G.J. (1997) Peracarid crustaceans from Cape d'Aguilar and Hong Kong, III. Tanaidacea: Tanaidomorpha In: Morton, B. (Ed.), The Marine Flora and Fauna of Hong Kong and Southern China IV. Proceedings of the Eighth International Marine Biological Workshop: The Marine Flora and Fauna of Hong Kong and Southern China, Hong Kong, 2-20 April 1995. Hong Kong University Press, Hong Kong, pp. 103-142.

Bamber, R.N. \& Chatterjee, T. (2010) The new and the old: littoral tanaidomorph Tanaidacea (Crustacea: Peracarida) from the Andaman Islands, Indian Ocean. Zootaxa, 2558 (1), 17-32. https://doi.org/10.11646/zootaxa.2558.1.2

Bamber, R.N. \& Błażewicz-Paszkowycz, M. (2013) Another inordinate fondness: diversity of the tanaidacean fauna of Australia, with description of three new species. Journal of Natural History, 47 (25-28), 1767-1789. https://doi.org/10.1080/00222933.2012.742164

Bax, N., Williamson, A., Aguero, M., Gonzales, E. \& Geeves, W. (2003) Marine invasive alien species: a threat to global biodiversity. Marine Policy, 27, 313-323. https://doi.org/10.1016/S0308-597X(03)00041-1

Bird, G.J. (2008) Untying the Gordian Knot: on Tanais novaezealandiae Thomson (Crustacea, Tanaidacea, Tanaidae) from New Zealand, with descriptions of two new Zeuxoides species. Zootaxa, 1877 (1), 1-36. https://doi.org/10.11646/zootaxa.1877.1.1

Bird, G.J. (2015) Tanaidacea (Crustacea: Peracarida) of the Kermadec Biodiscovery Expedition 2011, with a new sub-family of Paratanaidae: Metatanainae. Bulletin of the Auckland Museum, 20, 369-404.

Available from: https:/www.aucklandmuseum.com/getmedia/0601558b-57e9-4e34-af50-2e4c99be0eb7/bulletin-vol20kermadec-biodiscovery-expedition-17-bird (accessed 24 November 2015).

Bird, G.J. (2019) Tanaidacea (Crustacea: Peracarida) from the Southern French Polynesia Expedition, 2014. I. Tanaidomorpha. Zootaxa, 4548 (1), 1-75.

https://doi.org/10.11646/zootaxa.4548.1.1

Błażewicz-Paszkowycz, M., Bamber, R.N. \& Anderson, G. (2012) Diversity of Tanaidacea (Crustacea: Peracarida) in the world's oceans - how far have we come? PLOS ONE, 7 (4), e33068. https://doi.org/10.1371/journal.pone.0033068

Burgin, S. \& Hardiman, N. (2011) The direct physical, chemical and biotic impacts on Australian coastal waters due to recreational boating. Biodiversity and Conservation, 20, 683-701. https://doi.org/10.1007/s10531-011-0003-6

Carlton, J.T. (1996) Pattern, process, and prediction in marine invasion ecology. Biological Conservation, 78, 97-106. https://doi.org/10.1016/0006-3207(96)00020-1

Carlton, J.T. \& Hodder, J. (1995) Biogeography and dispersal of coastal marine organisms: experimental studies on a replica of a $16^{\text {th }}$ Century sailing vessel. Marine Biology, 121, 721-730. 
https://doi.org/10.1007/BF00349308

Chan, F.T., MacIsaac, H.J. \& Bailey, S.A. (2015) Relative importance of vessel hull fouling and ballast water as transport vectors of nonindigenous species to the Canadian Arctic. Canadian Journal of Fisheries and Aquatic Science, 72, 1230-1242. https://doi.org/10.1139/cjfas-2014-0473

Chapman, J.W., Breitensen, R.A. \& Carlton, J.T. (2013) Port-by-port accumulations and dispersal of hull fouling invertebrates between the Mediterranean Sea, the Atlantic Ocean, and the Pacific Ocean. Aquatic Invasions, 8 (3), 249-260. https://doi.org/10.3391/ai.2013.8.3.01

Coutts, A.D.M., Moore, K.M. \& Hewitt, C.L. (2003) Ships' sea-chests: an overlooked transfer mechanism for non-indigenous marine species? Marine Pollution Bulletin, 46, 1504-151. https://doi.org/10.1016/S0025-326X(03)00292-3

Darling, J. A. \& Carlton, J. T. (2018) A Framework for Understanding Marine Cosmopolitanism in the Anthropocene. Frontiers in Marine Science, 5 (293). https://doi.org/10.3389/fmars.2018.00293

Dollfus, A. (1897) Note préliminaire sur les Tanaidae recueillis aux Açores pendant les Campagnes de 1'Hirondelle (18871888). Bulletin de la Société Zoologique de France, 22, 207-215. Available from: https://www.biodiversitylibrary.org/page/3064476 (accessed 24 October 2017)

Drumm, D.T. (2010) Phylogenetic relationship of Tanaidacea (Eumalacostraca: Peracarida) inferred from three molecular loci. Journal of Crustacean Biology, 30 (4), 692-698. https://doi.org/10.1651/10-3299.1

Dudich, E. (1931) Systematische und biologische Untersuchungen über die Kalkeinlagerungen des Crustaceenpanzers im polarisierten Lichte. Zoologica, 80, 1-154.

Edgar, G.J. (2008) Shallow water Tanaidae (Crustacea: Tanaidacea) of Australia. Zootaxa, 1836, 1-92. https://doi.org/10.11646/zootaxa.1836.1.1

Esquete, P. \& Fernandez-Gonzalez, V. (2016) Description, systematics, and ecology of a new tanaidacean (Crustacea: Peracarida) species from Mediterranean fish farms. Helgoland Marine Research, 70, 27. https://doi.org/10.1186/s10152-016-0480-9

Folmer, O., Black, M., Hoeh, W., Lutz, R. \& Vrijenhoek, R. (1994) DNA primers for amplification of mitochondrial cytochrome c oxidase subunit I from diverse metazoan invertebrates. Molecular Marine Biology and Biotechnology, 3, $294-299$.

García-Herrero, A., Sánchez, N., García-Gómez, G., Pardos, F. \& Martínez, A. (2017) Two new stygophilic tanaidomorphs (Peracarida, Tanaidacea) from Canary Islands and southeastern Iberian Peninsula. Marine Biodiversity, 49 (1), $107-130$. https://doi.org/10.1007/s12526-017-0763-7

Geburzi, J.C. \& McCarthy, M.L. (2018) How do they do it?-Understanding the success of marine invasive species. In: Jungblut, S., Liebich, V. \& Bode-Dalby, M. (Eds.), YOUMARES 8-Oceans Across Boundaries: Learning from each other. Springer International, Cham, pp. 109-124. https://doi.org/10.1007/978-3-319-93284-2_8

Geller, J.B., Darling, J.A. \& Carlton, J.T. (2010) Genetic Perspectives on Marine Biological Invasions. Annual Review of Marine Science, 2, 367-393. https://doi.org/10.1146/annurev.marine.010908.163745

Glasby, T.M., Connell, S.D., Holloway, M.G. \& Hewitt, C.L. (2007) Nonindigenous biota on artificial structures: could habitat creation facilitate biological invasions? Marine Biology, 151, 887-895. https://doi.org/10.1007/s00227-006-0552-5

Haswell, W.A. [1881 (1882)] On some new Australian marine Isopoda- Part II. Proceedings of the Linnean Society of New South Wales, 6, 181-197. Available from: https://www.biodiversitylibrary.org/page/3343922\#page/203/mode/1up (accessed 15 April 2020) https://doi.org/10.5962/bhl.part.11867

Hewitt, C.L., Campbell, M.L., Thresher, R.E., Martin, R.B., Boyd, S., Cohen, B.F., Currie, D.R., Gomon, M.F., Keough, M.J., Lewis, J.A., Lockett, M.M., Mays, N., McArthur, M.A., O’Hara, T.D., Poore, G.C.B., Ross, D. J., Storey, M.J., Watson, J.E. \& Wilson, R.S. (2004) Introduced and cryptogenic species in Port Phillip Bay, Victoria, Australia. Marine Biology, $144,183-202$. https://doi.org/10.1007/s00227-003-1173-x

Hutchings, P.A., Ward, T.J., Waterhouse, J.H. \& Walker, L. (1993) Infauna of marine sediments and seagrass beds of upper Spencer Gulf near Port Pirie, South Australia. Transactions of the Royal Society of South Australia, 117, 1-15. Available from: https://www.biodiversitylibrary.org/page/41262660\#page/5/mode/1up (accessed 15 December 2020).

Ivanova, N.V., Dewaard, J.R. \& Hebert, P.D.N. (2006) An inexpensive, automation-friendly protocol for recovering high-quality DNA. Molecular Ecology Notes, 6, 998-1002. https://doi.org/10.1111/j.1471-8286.2006.01428.x

Kakui, K., Katoh, T., Hiruta, S.F., Kobayashi, N. \& Kajihara, H. (2011) Molecular systematics of Tanaidacea (Crustacea: Peracarida) based on $18 \mathrm{~S}$ sequence data, with an amendment of Suborder/Superfamily-level classification. Zoological Science, 28, 749-757. https://doi.org/10.2108/zsj.28.749

Kakui, K., Hayakawa, Y. \& Katakura, H. (2017) Difference in size at maturity in annual and overwintering generations in the 
Tanaidacean Zeuxo sp. in Oshoro Bay, Hokkaido, Japan. Zoological Science, 34, 129-136.

https://doi.org/10.2108/zs160134

Kudinova-Pasternak, R.K. (1989) A supplement to the fauna of Tanaidacea (Crustacea) of Kurile Islands and the description of Zeuxo beringi sp. n. (Commander Islands). Zoologicheskii Zhurnal, 68, 128-30.

Kumar, S., Stecher, G. \& Tamura, K. (2016) MEGA 7: Molecular Evolutionary Genetic Analysis version 7 for bigger datasets. Molecular Biology and Evolution, 33, 1870-1874.

https://doi.org/10.1093/molbev/msw054

Kussakin, G.O. \& Tzareva, L.V. (1974) On the fauna of Tanaidacea (Crustacea, Tanaidacea) from the intertidal zone of the Kurile Islands. In: Symposium No. 1: Fauna and Flora of the Near Shore Zone of the Kurile Islands. Academy of Sciences, USSR, Far Eastern Science Center, Institute of Marine Biology, pp. 215-226.

Larsen, K. (2001) Morphological and molecular investigation of polymorphism and cryptic species in tanaid crustaceans: implications for tanaid systematics and biodiversity estimates. Zoological Journal of the Linnean Society, 131, 353-379. https://doi.org/10.1006/zjls.2000.0235

Larsen, K. (2003) Proposed new standardized anatomical terminology for the Tanaidacea (Peracarida). Journal of Crustacean Biology, 23 (3), 664-661. https://doi.org/10.1651/C-2363

Larsen, K. (2005) Deep-sea Tanaidacea (Peracarida) from the Gulf of Mexico. Crustaceana Monographs. Vol. 5. Brill, Leiden, $381 \mathrm{pp}$.

Larsen, K. (2014) New species of the genus Zeuxo (Peracarida, Tanaidacea). Crustaceana, 87 (6), 715-754. https://doi.org/10.1163/15685403-00003310

Larsen, K. \& Froufe, E. (2010) Identification of polymorphic species within groups of morphologically conservative taxa: combining morphological and molecular techniques. In: Nimis, P.L. \& Vignes Lebbe, R. (Eds.) Tools for Identifying Biodiversity: Progress and Problems. Proceedings of the International Congress, Paris, 20-22 September 2010, EUT. pp. 301-305.

Larsen, K., Tuya, F. \& Froufe, E. (2014) Genetic divergence of tanaidaceans (Crustacea: Peracarida) with low dispersal ability. Scientia Marina, 78 (1), 81-90. https://doi.org/10.3989/scimar.03878.19A

Larsen, K., Guţu, M. \& Sieg, J. (2015) Order Tanaidacea Dana, 1849. In: Von Vaupel Klein, J.C., Charmentier-Daurés, M. \& Schram, F.R. (Eds.), Treatise on Zoology-Anatomy, Taxononomy, Biology. The Crustacea. Vol. 5. Koninklijke Brill NV, Leiden, pp. 249-329.

https://doi.org/10.1163/9789004232518_007

Latreille, P.A. (1831) Hétéropodes (Heteropoda). In: Latreille, P.A. (Ed.), Cours d'Entomologie, ou de l'Histoire Naturelle des Crustacés, des Arachnides, des Myriapodes et des Insects; a 1'Usage des Élèves de 1'Ecole du Muséum d'Histoire Naturelle. Librairie de Roret, Paris, pp. 403. https://doi.org/10.5962/bhl.title.119919

Leclerc, J.-C., Viard, F., González Sepúlveda, E., Díaz, C., Neira Hinojosa, J., Pérez Araneda, K., Silva, F. \& Antonio, B. (2020) Habitat type drives the distribution of non-indigenous species in fouling communities regardless of associated maritime traffic. Diversity and Distributions, 26, 62-75. https://doi.org/10.1111/ddi.12997

Marchini, A. \& Cardeccia, A. (2017) Alien amphipods in a sea of troubles: cryptogenic species, unresolved taxonomy and overlooked introductions. Marine Biology, 164 (4), 69. https://doi.org/10.1007/s00227-017-3093-1

Martínez-Laiz, G., Ros, M. \& Guerra-García, J.M. (2018) Marine exotic isopods from the Iberian Peninsula and nearby waters. PeerJ, 6, e4408. https://doi.org/10.7717/peerj. 4408

Miller, M.A. (1940) The isopod Crustacea of the Hawaiian Islands (Chelifera and Valvifera. Occasional Papers of the Bernice P. Bishop Museum, Honolulu, 15 (26), 295-321. Available from: http://hbs.bishopmuseum.org/pubs-online/pdf/op15-26.pdf (accessed 24 October 2017)

Moore, H.F. (1894) Tanais robustus, a new species of Anisopoda. Proceedings of the Academy of Natural Sciences of Philadelphia, 46, 90-94. Available from: https://www.biodiversitylibrary.org/item/18073 (accessed 20 November 2019)

Morales-Vela, B., Suárez-Morales, E., Padilla-Saldívar, J. \& Heard, R.W. (2008) The tanaid Hexapleomera robusta (Crustacea: Peracarida) from the Caribbean manatee, with comments on other crustacean epibionts. Journal of the Marine Biological Association of the United Kingdom, 88 (3), 591-596.

https://doi.org/10.1017/S0025315408000672

National Center for Biotechnology Information (NCBI). Nucleotide Database, Available from: https://www.ncbi.nlm.nih.gov/ nucleotide (accessed 20 April 2021)

Nishiguchi, M.K., Doukakis, P., Egan, M., Kizirian, D., Phillips, A., Prendini, L., Rosenbaum, H.C., Torres, E., Wyner, Y., DeSalle, R. \& Giribet, G. (2002) DNA Isolation Procedures. In: DeSalle, R. (Ed.), Methods and Tools in Biosciences and Medicine. Techniques in Molecular Systematics and Evolution. Birkhauser Verlag, Basel, pp. 250-287. https://doi.org/10.1007/978-3-0348-8125-8_12

Nobili, G. (1906) Diagnoses préliminaires de Crustacés, Décapodes et Isopodes nouveaux recueillis par M. le Dr. G. Seurat aux 
îles Touamotou. Bulletin du Muséum National d'Histoire Naturelle, 12 (12), 256-270. Available from: http://www.marinespecies.org/aphia.php?p=sourcedetails\&id=46679 (accessed 17 December 2019)

https://doi.org/10.5962/bhl.part.4097

Nordenstam, A. (1930) Tanaidacea and Marine Isopoda from Juan Fernandez. In: Skoltsberg, C. (Ed.), The Natural History of Juan Fernandez and Easter Island. Vol. III. Almquist \& Wiksells Bogtrckeri-A-B, Uppsala, pp. 525-552.

Occhipinti-Ambrogi, A. \& Galil, B. (2010) Marine alien species as an aspect of global change. Advances in Oceanography \& Limnology, 1, 199-218. https://doi.org/10.1080/19475721003743876

Okamoto, N., Oya, Y. \& Kakui, K. (2020) A new species of Zeuxo (Crustacea: Peracarida: Tanaidacea) from Japan, with remarks on carapace pigmentation as a potentially useful taxonomic character. Marine Biology Research, 16 (5), 411-422. https://doi.org/10.1080/17451000.2020.1766693

Rech, S., Borrell Pichs, Y.J. \& García-Vazquez, E. (2018) Anthropogenic marine litter composition in coastal areas may be a predictor of potentially invasive rafting fauna. PLoS ONE, 13, e0191859. https://doi.org/10.1371/journal.pone.0191859

Richardson, H. (1901) Papers from the Hopkins Stanford Galapagos Expedition, 1898-1899. VI. The isopods. Proceedings of the Washington Academy of Sciences, 3, 565-568. Available from: https://www.biodiversitylibrary.org/page/8873497 (accessed 16 February 2015) https://doi.org/10.5962/bhl.part.26343

Richardson, H. (1905) Description of a new genus of Isopoda belonging to the family Tanaidae and of a new species of Tanais, both from Monterey Bay, California. Proceedings of the United States National Museum, 28 (1400), 367-370. Available from: https://www.biodiversitylibrary.org/item/52788\#page/7/mode/1up (acessed 23 December 2014) https://doi.org/10.5479/si.00963801.28-1400.367

Ruiz, G.M., Fofonoff, P.W., Steves, B.P. \& Carlton, J.T. (2015) Invasion history and vector dynamics in coastal marine ecosystems: A North American perspective. Aquatic Ecosystem Health \& Management, 18, 299-311. https://doi.org/10.1080/14634988.2015.1027534

Rumbold, C.E., Obenat, S.M. \& Spivak, E.D. (2012) Life history of Tanais dulongii (Tanaidacea: Tanaidae) in an intertidal flat in the southwestern Atlantic. Journal of Crustacean Biology, 32 (6), 891-898. https://doi.org/10.1163/1937240X-00002094

Rumbold, C.E., Obenat, S.M. \& Spivak, E.D. (2014) Morphometry and relative growth of populations of Tanais dulongii (Audouin, 1826) (Tanaidacea: Tanaidae) in pristine and impacted marine environments of the southwestern Atlantic. Journal of Crustacean Biology, 34 (5), 581-592. https://doi.org/10.1163/1937240X-00002265

Rumbold, C.E., Obenat, S.M. \& Spivak, E.D. (2015a) Comparison of life history traits of Tanais dulongii (Tanaidacea: Tanaididae) in natural and artificial marine environments of the south-western Atlantic. Helgoland Marine Research, 69, 231-242. https://doi.org/10.1007/s10152-015-0432-9

Rumbold, C.E., Obenat, S.M., Leonardi, M.S. \& Spivak, E.D. (2015b) Intersex in the gonochoristic crustacean Tanais dulongii (Audouin, 1826) (Peracarida: Tanaidacea: Tanaididae): a comparison of external reproductive characteristics. Journal of Natural History, 49 (13-14), 775-788. https://doi.org/10.1080/00222933.2014.981309

Sieg, J. (1980) Taxonomische Monographie der Tanaidae DANA 1849 (Crustacea: Tanaidacea). In: Abhandlungen der Senckenbergischen Naturforschenden Gesellschaft. Vol. 537. Verlag, Frankfurt, 267 pp.

Tanabe, Y., Hayashi, R., Tomioka, S. \& Kakui, K. (2017) Hexapleomera urashima sp. nov. (Crustacea: Tanaidacea), a tanaidid epibiotic on loggerhead sea turtles at Yakushima Island, Japan. Zootaxa, 4353 (1), 146-160. https://doi.org/10.11646/zootaxa.4353.1.9

Tanabe, Y. \& Kakui K. (2019) Two Hexapleomera species from Japan, with a new species descriptions and discussion of phylogenetic relationships within Hexapleomera (Crustacea: Tanaidacea). Zootaxa, 4648 (2), 381-336. https://doi.org/10.11646/zootaxa.4648.2.7

Templeton, R. (1840) Description of a minute crustaceous animal from the Island of Mauritius. The Transactions of the Entomological Society of London, 2 (4), 203-207. https://doi.org/10.1111/j.1365-2311.1836.tb00326.x

Thomson, G.M. (1879) On two new Isopods (Arcturus sp. and Tanais sp.) from New Zealand. Annals and Magazine of Natural History, London, Series 5, 4 (24), 415-418. https://doi.org/10.1080/00222937908679860

Thomson, J.M. (1944) The fauna of the algal zone of the Swan River Estuary. A preliminary survey of Freshwater Bay with notes on the chief species. Journal of the Royal Society of Western Australia, 30, 55-73.

Available from: https://www.biodiversitylibrary.org/item/201167 (accessed 4 February 2020)

Tzeng, Y.-W. \& Hsueh, P.-W. (2014) Two new species of Tanaidacea (Crustacea, Peracarida) from Taiwan. Zootaxa, 3802 (1), 51-64.

https://doi.org/10.11646/zootaxa.3802.1.4

Tzeng, Y.-W. \& Hsueh, P.-W. (2015) Additions of new species and records to the Tanaidomorpha (Crustacea: Tanaidacea) of 
Taiwan. Zootaxa, 4013 (1), 27-50.

https://doi.org/10.11646/zootaxa.4013.1.2

Ulman, A., Ferrario, J., Occhipinti-Ambrogi, A., Arvanitidis, C., Bandi, A., Bertolino, M., Bogi, C., Chatzigeorgiou, G., Çiçek, B.A., Deidun, A., Ramos-Esplá, A., Koçak, C., Lorenti, M., Martínez-Laiz, G., Merlo, G., Princisgh, E., Scribano, G. \& Marchini, A. (2017) A massive update of non-indigenous species records in Mediterranean marinas. PeerJ, 5 , e3954. https://doi.org/10.7717/peerj.3954

Van Haaren, T. \& Soors, J. (2009) Sinelobus stanfordi (Richardson, 1901): A new crustacean invader in Europe. Aquatic Invasions, 4 (4), 703-711. https://doi.org/10.3391/ai.2009.4.4.20

Walsh, P.S., Metzger, D.A. \& Higuchi, R. (1991) Chelex-100 as a medium for simple extraction of DNA for PCR-based typing from forensic material. BioTechniques, 10 (4), 506-513.

Wang, Q. \& Wang, X. (2012) Comparison of methods for DNA extraction from a single chironomid for PCR analysis. Pakistan Journal of Zoology, 44 (2), 421-426. Available from: http://zsp.com.pk/pdf44/421-426\%20_18_\%20PJZ-680-11.pdf (accessed 6 May 2014).

Ward, T.J. \& Hutchings, P.A. (1996) Effects of trace metals on infaunal species composition in polluted intertidal and subtidal marine sediments near a lead smelter, Spencer Gulf, South Australia. Marine Ecology Progress Series, 135, $123-135$. https://doi.org/10.3354/meps135123

Wasson, K., Zabin, C.J., Bedinger, L., Cristina Diaz, M. \& Pearse, J.S. (2001) Biological invasions of estuaries without international shipping: the importance of intraregional transport. Biological Conservation, 102, 143-153. https://doi.org/10.1016/S0006-3207(01)00098-2

Wells, F.E., McDonald, J.I. \& Huisman, J.M. (2009) Introduced Marine Species in Western Australia. Fisheries Occasional Publications No. 57. February 2009. Department of Fisheries, Perth, Western Australia, 98 pp.

Wi, J.H., Jeong, M.-K. \& Kang, C.-K. (2018a) A new species of the genus Hexapleomera Dudich, 1931 from the South Korea, with molecular evidence (Crustacea, Tanaidacea, Tanaididae). ZooKeys, 739, 1-28. https://doi.org/10.3897/zookeys.739.21580

Wi, J.H., Kang, C.-K., Lee, I.T. \& Jeong, H.G. (2018b) Re-evaluation of morphological diagnostic characteristics of Hexapleomera Dudich, 1931 (Crustacea: Tanaidacea), with description of a new species. Ocean Science Journal, 53 (4), $641-653$. https://doi.org/10.1007/s12601-018-0039-6

Wi, J.H., Jeong, M-K. \& Jeong, H.G. (2018c) Two new species of the genus Zeuxo (Peracarida: Tanaidacea) from the west and south coast of Korea. Marine Biodiversity, 48, 1097-1108. [published online 2016] https://doi.org/10.1007/s12526-016-0556-4

Wiltshire, K., Rowling, K. \& Deveney, M. (2010) Introduced marine species in South Australia: a review of records and distribution mapping. South Australian Research and Development Institute (Aquatic Sciences). Adelaide. SARDI Publication No. F2010/000305-1. SARDI Research Report Series No. 468. South Australian Research and Development Institute (Aquatic Sciences), Adelaide, pp 232.

WoRMS (2021) Tanais Latreille, 1831; Zeuxo Templeton, 1840; Hexapleomera Dudich, 1931. Available from: http://www. marinespecies.org/aphia.php (accessed 30 April 2021) 